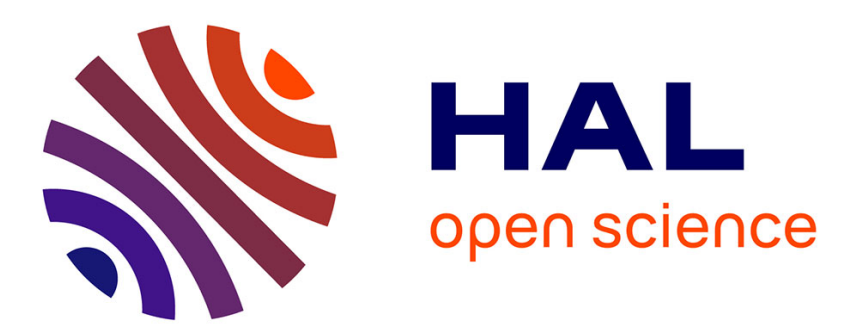

\title{
Moisture balance assessment at room scale for four cases based on numerical simulations of HAM transfers for a realistic occupancy scenario
}

\author{
Matthieu Labat, Monika Woloszyn
}

\section{- To cite this version:}

Matthieu Labat, Monika Woloszyn. Moisture balance assessment at room scale for four cases based on numerical simulations of HAM transfers for a realistic occupancy scenario. Journal of Building Performance Simulation, 2015, 9 (5), pp.487 - 509. 10.1080/19401493.2015.1107136 . hal-01785401

\author{
HAL Id: hal-01785401 \\ https://hal.science/hal-01785401
}

Submitted on 4 May 2018

HAL is a multi-disciplinary open access archive for the deposit and dissemination of scientific research documents, whether they are published or not. The documents may come from teaching and research institutions in France or abroad, or from public or private research centers.
L'archive ouverte pluridisciplinaire HAL, est destinée au dépôt et à la diffusion de documents scientifiques de niveau recherche, publiés ou non, émanant des établissements d'enseignement et de recherche français ou étrangers, des laboratoires publics ou privés. 


\title{
Moisture balance assessment at room scale for four cases based on numerical simulations of HAM transfers for a realistic occupancy scenario
}

\author{
Matthieu Labat ${ }^{1,2,3, *}$, Monika Woloszyn ${ }^{4}$ \\ ${ }^{1}$ Université de Lyon, 69361 Lyon Cedex 07, France
}

${ }^{2}$ CETHIL UMR5008, INSA-Lyon, Université Lyon 1, Bât. Sadi Carnot, 9 rue de la physique, 69621 Villeurbanne Cedex, France

${ }^{3}$ Université de Toulouse; UPS, INSA;LMDC (Laboratoire Matériaux et Durabilité des Constructions);135, avenue de Rangueil;F-31077 Toulouse Cedex 04, France

${ }^{4}$ Univ. Savoie, LOCIE, F-73000 Chambéry, France, CNRS, LOCIE, F-73000 Chambéry, France

\begin{abstract}
The moisture balance at room scale is influenced by the air change rate, moisture production and vapour transfer with the envelope. However, results may differ strongly from one study to another depending on the sizing of the ventilation system, the boundary conditions and the modelling of vapour transfer in the walls. This paper aims to provide a realistic comparison of usual construction techniques based on energy consumption, indoor comfort and durability. To achieve this objective, an existing whole-building heat-air-moisture simulation tool was selected to compute coupled transfer at room scale over an entire year. Moisture production due to occupancy was modelled using a stochastic approach. Four cases were selected to emphasise the differences of both a vapour permeable wall assembly and a relative humidity sensitive (RHS) ventilation system compared to common practices.
\end{abstract}

\section{Keywords}


Numerical model, probabilistic occupancy scenario, hygroscopic insulation, relative humidity sensitive ventilation, indoor comfort, wooden-frame house,

\section{Nomenclature}

\section{LATIN SYMBOLS}

$\begin{array}{lll}\mathrm{AH} & \text { Absolute humidity } & \left(\mathrm{kg}_{\text {Vap }} \cdot \mathrm{kg}_{\text {DryAir }}{ }^{-1}\right) \\ \mathrm{Cp} & \text { Heat capacity } & \left(\mathrm{J}_{\mathrm{kg}}^{-1} \cdot \mathrm{K}^{-1}\right) \\ \mathrm{g} & \text { Mass flux } & \left(\mathrm{kg} \cdot \mathrm{m}^{-2} \cdot \mathrm{s}^{-1}\right) \\ \mathrm{H} & \text { Enthalpy } & (\mathrm{J}) \\ \mathrm{h} & \text { Surface heat transfer coefficient } & \left(\mathrm{W} \cdot \mathrm{m}^{-2} \cdot \mathrm{K}^{-1}\right) \\ \mathrm{h}_{\mathrm{m}} & \text { Surface mass transfer coefficient } & \left(\mathrm{kg} \cdot \mathrm{m}^{-2} \cdot \mathrm{s}^{-1} \cdot \mathrm{Pa}^{-1}\right) \\ \mathrm{m} & \text { Mass } & (\mathrm{kg}) \\ \mathrm{p} & \text { Pressure } & (\mathrm{Pa}) \\ \mathrm{q} & \text { Heat flux } & \left(\mathrm{W} \cdot \mathrm{m}^{-2}\right) \\ \mathrm{T} & \text { Temperature } & \left(\mathrm{K} \mathrm{or}^{\circ} \mathrm{C}\right) \\ \mathrm{V} & \text { Volume } & \left(\mathrm{m}^{3}\right) \\ \mathrm{w} & \text { Moisture content } & \left(\mathrm{kg} \cdot \mathrm{m}^{-3}\right)\end{array}$

\section{GREEK SYMBOLS}

$\delta \quad$ Vapour permeability

(s)

$\lambda$ Thermal conductivity

$\lambda_{\mathrm{W}} \quad$ Humid thermal conductivity

(W. $\left.\mathrm{m}^{-1} \cdot \mathrm{K}^{-1}\right)$

$\rho \quad$ Density

$\left(\mathrm{W} \cdot \mathrm{m}^{-1} \cdot \mathrm{K}^{-1} \cdot\left(\mathrm{kg} \cdot \mathrm{m}^{3}\right)^{-1}\right)$

$\psi \quad$ Relative humidity

$\left(\mathrm{kg} \cdot \mathrm{m}^{-3}\right)$

$(-)$

\section{SUBSCRIPTS}

Cond Conductive

D Measured on dry material

In Indoor

Irr Irradiative

Mat Material

Out Outdoor

v Vapour

\section{CONSTANTS}

$\mathrm{L}_{\mathrm{V}} \quad$ Latent heat of vapour condensation $\left(2500.10^{3} \mathrm{~J}_{\mathrm{kg}} \mathrm{kg}^{-1}\right)$

$\mathrm{p}_{\text {Tot }} \quad$ Total pressure $\quad(101325 \mathrm{~Pa})$

$\mathrm{r}_{\text {Dry }} \quad$ Dry air constant $\quad\left(287 \mathrm{~J} \cdot \mathrm{kg}^{-1} \cdot \mathrm{K}^{-1}\right)$

$\mathrm{r}_{\mathrm{V}} \quad$ Vapour constant $\quad\left(462 \mathrm{~J} \cdot \mathrm{kg}^{-1} \cdot \mathrm{K}^{-1}\right)$

\section{Introduction}

The topic of energy savings continues to be of widespread concern, especially in the field of building physics. Over the last few decades, this on-going discussion has included heat 
transfer and other aspects of construction that must all be considered in today's context. The impact of vapour transfer and its storage within walls on indoor moisture balance forms an integral and challenging part of the discussion because it simultaneously impacts heat transfer, indoor comfort and the durability of wall assemblies. As stated by Diasty, Fazio, and Budaiwi (1992), this balance is influenced by numerous transfers acting simultaneously with different time constants. The most important factors influencing indoor moisture balance are: (1) moisture interactions between indoor air and materials, (2) ventilation systems, and (3) indoor moisture sources. Therefore, any realistic assessment of moisture balance on a room or at whole building scale must appropriately represent these three phenomena. Moreover, the influence of a particular transfer on the moisture balance depends on many factors, making it difficult to generalise to all kinds of buildings and conditions. The development and use of comprehensive numerical models is thus very important.

\subsection{Vapour exchanges between air and materials}

The buffering capacity of hygroscopic material is a well-known effect of moisture interaction between indoor air and materials that has already been discussed by numerous authors. It represents the ability of the materials (interior objects, finishing, etc.) to adsorb and release moisture when exposed to a variation of relative humidity and so to smooth indoor relative humidity variations. In the literature, this effect has been estimated by using various experimental protocols and numerical approaches. Moisture Buffering Value (MBV) assessment is a widespread experimental protocol, presented by Rode et al. (2005), where small samples are subjected to relative humidity cycles. A comparison with a similar protocol developed in Japan is proposed by Roels and Janssen (2006). Measurements at room scale were taken by Yoshino, Mitamura, and Hasegawa (2009) to study the buffering capacity of gypsum boards, and then of walls composed of clay mineral by Zhang, Yoshino, and Hasegawa (2012). As the MBV value is determined for small samples placed in a climatic 
chamber at controlled humidity and temperature, it was not suitable to represent these latest measurements. The authors therefore defined two dimensionless indexes, the Moisture Adsorption effect (MBEa) and the Moisture Desorption effect (MBEd), to better represent the buffering effect at room scale. Similar experimental work has been conducted by Yang Li, Fazio, and Rao (2012). Another index was proposed, namely the Effective Dampened Relative Humidity (EDRH). The same experimental apparatus was used by Yang et al. (2012) to compare the moisture buffering of uncoated gypsum boards and wood panelling based on the calculation of the Maximum Accumulated Buffering Value (MAMBV). The dependence of the MAMBV on the air change rate and the moisture production rate was highlighted. Based on the definition of the Hygric Inertia of a Room (HIR) (Janssen and Roels, 2009), the moisture buffering of room enclosures was measured by Vereecken, Roels, and Janssen (2011) for various materials, including wood fibre board but also newspapers and books. It should be underlined that, in the above-mentioned studies, the buffering capacity was limited to vapour exchange with indoor finishing and interior objects (furniture, carpets, etc.); vapour was not allowed to move across the wall because of the use of a vapour barrier (aluminium or polyethylene sheets). At building scale, Carey J. Simonson, Salonvaara, and Ojanen (2001) studied moisture transfers in a real building in Finland for 15 days. In this case, no vapour barrier was used and satisfactory moisture contents were obtained for the indoor air and building structures. No specific index was proposed, but the discussion focused on the frequency distribution of indoor relative humidity and on the moisture accumulation in the structure. Orosa and Baaliña (2009) monitored indoor conditions in a Spanish bank office building over a 1-year period. The analysis focused on comfort indexes such as the Perceived indoor Air Quality (PAQ) and the Percentage of Dissatisfaction (PD). The buffering capacity of hygroscopic coverings was highlighted but was not explicitly estimated. Overall, it seems that the buffering capacity of hygroscopic materials can be estimated by different 
methodologies.

A review of numerical studies reveals a variety of approaches, ranging from simplified models of buffering capacities to detailed computation of coupled transfer in porous media. According to Vereecken, Roels, and Janssen (2011) two simplified models still prevail: the Effective Moisture Penetration Depth (EMPD) and the Effective Capacitance (EC). In the case of an airtight room with a well-defined moisture generation schedule, Vereecken, Roels, and Janssen (2011) showed that indoor relative humidity was correctly predicted by the EMPD model. This model was also used by Abadie and Mendonça (2009) and similar conclusions were obtained. However, as mentioned by the authors, this model relies on strong assumptions, namely the need to consider an isothermal case, constant moisture diffusivity and a well adapted thickness. This is in agreement with the conclusions presented by Janssens and De Paepe (2005). Other lumped approaches can be found in the literature (Diasty, Fazio, and Budaiwi, 1992; Emmerich, Persily, and Nabinger, 2002; Plathner and Woloszyn, 2002; Ghali, Katanani, and Hindi, 2011). More detailed approaches have already been proposed. Assuming sinusoidal input conditions, Isetti, Laurenti, and Ponticello (1988) solved the indoor moisture balance analytically by using Fourier harmonic analysis. However, numerical approaches dedicated to coupled heat-air-moisture (HAM) phenomena are far more common. This could be related to the availability of numerous models with different degrees of simplification, assumed according to the purpose of the study. A detailed comparison of these models has been made by Woloszyn and Rode (2008). A few examples are presented below to illustrate how such models can help to address the issues mentioned at the beginning of this paper. The material properties of a massive wood wall are defined in great detail by Hameury (2005) and integrated in the IDA environment in order to precisely model vapour transfer. The buffering capacity is characterised by introducing the buffering effect ratio, and its sensitivity to the air change rate is discussed. Roels and Janssen (2006) have calculated the 
water vapour transfer with the materials, using a finite element model. A model for predicting coupled multi-zone hygrothermal-airflow transfer was presented by Qin et al. (2011). The coupled system model was implemented into Matlab-Simulink and was validated by using a series of testing tools and experiments. WUFI commercial code is a widespread tool, and was used by Ge et al. (2014) to investigate the influence of moisture load profiles on the buffering capacity of ten materials. However, few studies relying on HAM-models have been dedicated to the estimation of buffering capacity only. In many cases, the numerical model is used to address more general issues such as the energy consumption of HVAC systems, the durability of a wall assembly or improving indoor comfort. For example, Karagiozis and Salonvaara (2001) developed a simulation code in order to model coupled heat and mass transfer at building scale. The study focused on an aerated concrete block home for two different interior vapour control strategies. The simulation took place over 3 years and a very high initial humidity level in the walls was assumed. By studying the evolution of the moisture content in the walls, the authors gave an estimation of the durability of the structure and of the energy required to maintain comfortable indoor conditions. The results showed that using a vapour barrier decreased the durability of the system. C. J. Simonson, Salonvaara, and Ojanen (2002) used a numerical code named LATENITE to investigate the influence of wood based indoor finishing on PAQ for four European climates and positive results were obtained. Casey et al. (2013) also used WUFI to assess the potential reduction in humidification/dehumidification energy demand for mesoporous silica materials. These are just some of the examples that can be found in the literature.

\subsection{Influence of the ventilation system and the moisture production}

Several studies have examined the influence of the ventilation system on indoor humidity at building scale. Based on measurements achieved over 2 years in more than 100 dwellings in Finland, Kalamees (2006) discussed the use of normative values. Several European standards 
describing the sizing of ventilation systems in dwellings have also been compared (Laverge, Pattyn, and Janssens 2013). Except for the British code, it was shown that the targeted air change rate was quite similar from one code to another, and close to 0.5 air change per hour (ach). Walker and Sherman (2007) computed the indoor humidity for various climates and ventilation systems, and discussed the efficiency of the ventilation systems. The specific case of relative humidity sensitive (RHS) ventilation was studied in detail by Woloszyn et al. (2009). Six different simulation tools were used to simulate both coupled transfer within the walls and the ventilation system. It was suggested that the management of indoor humidity could be improved by using a combination of both RHS ventilation and the buffering capacity of the walls.

\subsection{Indoor moisture sources}

Concerning indoor moisture production, there is also a wide range of schedules, from very simplified to more realistic ones. The simplest schedule uses a constant moisture production rate. This was proposed by TenWolde and Walker (2001) in order to include indoor humidity in the regulation codes and standards. Walker and Sherman (2007) estimated the average moisture production of a family of four by reviewing 9 studies. They concluded that a value of $270 \mathrm{~g} \cdot \mathrm{h}^{-1}$ was representative of the moisture production and considered a constant rate for a 1-year simulation. The moisture production was measured by Lu (2003) in a real inhabited log house located in Finland. The author concluded that continuous vapour production could be used to model the real production, rather than using a detailed scenario. On the other hand, a cyclic schedule has been preferred in many reviewed studies, either experimental or numerical (Carey J. Simonson, Salonvaara, and Ojanen, 2001; Salonvaara, Karagiozis, and Holm, 2001; Karagiozis and Salonvaara, 2001; C. J. Simonson, Salonvaara, and Ojanen, 2002; Hameury, 2005; Woloszyn et al., 2009; Steeman, Janssens, and De Paepe, 2009; Vereecken, Roels, and Janssen, 2011). Typical cyclic schedules have been designed to represent the building's 
occupancy by using a constant production rate for a few hours followed by a period with no (or a much lower rate of) moisture production resulting in a $24 \mathrm{~h}$ cycle. Most of the time, a single cycle was defined and repeated for the total duration of the simulation. It was observed that the duration and the production rate differed slightly from one study to another; this will be discussed more in detail in section 3.4. A noticeably different moisture production schedule can be found for the modelling of big buildings. Isetti, Laurenti, and Ponticello (1988) studied a 400-m² one-storey office occupied by up to 170 persons . For this particular case, significantly higher production rates were considered. In (Janssen and Roels 2009), a library was considered where the number of visitors varied continually. Therefore, a nonuniform production scheme was preferred but this was not discussed in much detail.

It is acknowledged in some studies that the duration of the production period significantly impacts the buffering effect (Roels and Janssen, 2006; Ge et al. ,2014). However, contradictory conclusions have also been drawn (Isetti, Laurenti, and Ponticello, 1988; Lu, 2003). It should be noted that the vapour transfer with the walls was not modelled in detail in either case. Isetti, Laurenti, and Ponticello (1988) used a lumped approach to compute the vapour transfer with the wall and an RHS ventilation system was modelled, which may have affected the results. For $\mathrm{Lu}$ (2003), the computed magnitude of vapour transfer with the walls was so low that it was finally neglected in the calculations. This raises questions about the influence of the moisture production schedule and the need to model it in detail or not.

Moreover, the use of cyclic schedules appears far from reality, particularly if the study deals with vapour transfer in a household where the moisture generation schedule can be very different from that of an office. Occupancy varies from one household to another and from one day to another. Such a deterministic scenario could be replaced with a stochastic approach, as has been done in many recent studies of energy performance simulation (Parys, Saelens, and Hens, 2011; Page et al., 2008). The stochastic approach is a general technique 
that also suits other purposes in the field of hygrothermal transfer, e.g. as presented by Salonvaara, Karagiozis, and Holm (2001). It is based on the knowledge of the probability density function of some of the inputs, which can be defined by an average value and its standard deviation. Then a random value can be calculated. By repeating this calculation, a wide range of probable inputs can be obtained, so the computed outputs can give a better understanding of the performance of "real" systems. Stochastic approaches for moisture simulations make up one of the topics investigated within the collaborative project, Annex 55 of the International Energy Agency (IEA). It was anticipated that the stochastic approach would be able to represent realistic moisture production correctly and would offer an interesting alternative to simplified schedules.

\subsection{Towards realistic assessment of moisture impact on building performance}

Numerous studies have been conducted on the impact of moisture on building or room performance, many of them using numerical simulations. Most of these studies include all three components of the moisture balance at room level, presented in sections 1.1 to 1.3. However most of the published studies concentrate on one of the three components and simplify the complementary aspects. To move the research forward, it now appears very important to launch studies where all three components are modelled with similar levels of detail. Such studies need to be conducted in order to gain better understanding of complex building behaviour and of possible interactions between different elements.

Therefore, the ambition of this paper is to assess moisture balance at room level and its impact on overall building performance, using detailed, realistic modelling of (1) moisture interactions between indoor air and materials, (2) ventilation systems, and (3) indoor moisture sources. 
In some cases, moisture interactions between indoor air and materials could be determined by using simplified approaches. For non-isothermal cases and/or vapour permeable walls, however, the use of models solving coupled heat and mass transfer through the construction appeared to be more relevant. In order to study the impact of the ventilation systems on building performance, two different types of mechanical ventilation were investigated. A constant flow system was compared with a system controlled by relative humidity. Furthermore, as stated, for example, by TenWolde and Walker (2001), the boundary conditions are important determinants for design recommendations. Indoor moisture production plays an important role here. Therefore, a stochastic approach, better representing real occupancy, was preferred to a deterministic scenario for moisture production. Because the benefit of using a detailed schedule for moisture production was not clearly demonstrated by the literature review, a comparison is proposed with results obtained using a constant moisture production rate.

For such a study, a comprehensive and reliable simulation tool is required. It is presumed that detailed simulations of Heat, Air and Moisture (HAM) transfers in the room air and wall assembly will enable relevant analyses to be carried out at different time scales (yearly and monthly) and spatial points (air / wall assembly). However, combined simulations of HAM transfers in wall assemblies and in rooms are rather complex. Therefore, conclusions as to whether the simulations successfully represent the physical reality should be based on thoughtful validation of the simulation tool. The starting point of the present work is therefore an experimental study on a test house, which allowed measurements and simulation results to be compared.

Section 2 briefly describes the initial step of this study, namely the simulation tool, the measurements taken on a wooden-frame house, and the model validation. Then section 3 introduces the methodology used to investigate the combined effect of (1) moisture 
interactions between indoor air and materials, (2) ventilation systems and (3) indoor moisture sources. A large part is devoted to the modelling of indoor moisture production. In the last section, the results are analysed in terms of comfort, durability and energy consumption. The analysis distinguishes between average behaviour (yearly scale) and phenomena occurring on a shorter time scale (monthly scale). Finally, the influence of the moisture production scenario is discussed.

\section{Experimental study and model validation}

In order to enhance the possible influence of vapour transfers, a hygroscopic and potentially vapour open construction, such as wooden frame walls, was preferred. We took advantage of previous work achieved on an experimental house exposed to natural climatic conditions in France (Piot et al. 2011; Labat et al. 2015). The experimental set-up was monitored for more than 3 years, making it suitable for the calibration of a numerical model. In this section, the experimental house is described briefly. Then, the numerical model is presented. Finally the last sub-section compares the experimental and numerical results at room scale.

\subsection{Building description and wall assemblies}

The experimental facility is located near Grenoble, France (latitude: $45.2^{\circ} \mathrm{N}$, longitude: $5.77^{\circ}$ E). The wooden-frame house (see Figure 1) is divided into one main room and a naturally ventilated attic. The dimensions of the main room were designed to be representative of a living room $\left(50 \mathrm{~m}^{3}\right)$. The instrumentation was designed to monitor heat and moisture flows across the vertical walls, mainly with thermo-hygrometers. To simplify the boundary conditions and to limit heat and vapour transfers through the horizontal walls, the floor was elevated above the ground and the insulation of both the ceiling and the floor was reinforced. The door of the test house, located in the middle of the northern face, was insulated with polystyrene so that the insulation level would be homogeneous on the whole face. To have 
homogeneous indoor conditions, a fan mixed the indoor air. Various occupation scenarios can be defined by means of a simple convective heater and a vapour generation system (cold mist generator). Finally, the structure is made of vertical spruce studs, positioned every $60 \mathrm{~cm}$. More details can be found in Piot et al. (2011).

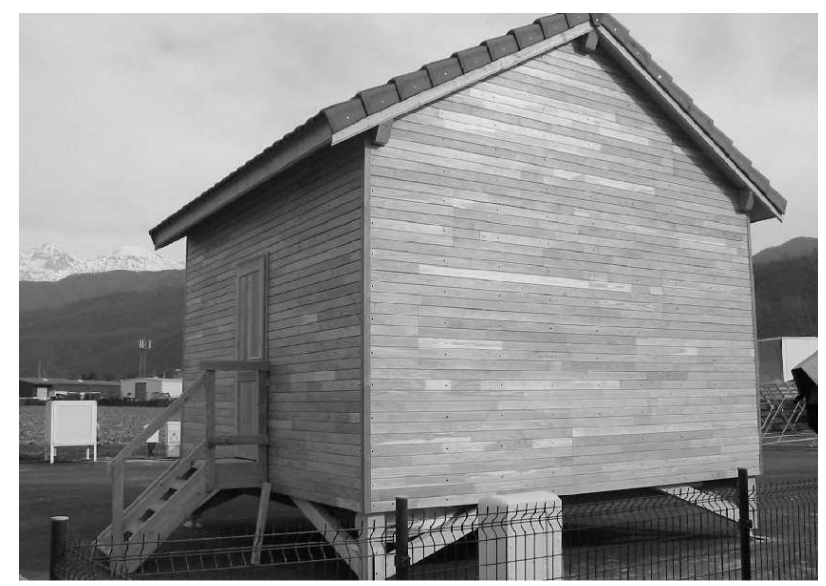

Figure 1: Picture of the experimental building (eastern and northern sides)

The wall assembly is representative of typical wooden-frame houses in France and is composed of the following layers (see Figure 2):

○ indoor siding (gypsum board, $13 \mathrm{~mm}$ );

○ a vapour barrier equivalent in terms of vapour diffusion to a 19-m-thick air layer;

$\circ$ an insulating material between the studs $(160 \mathrm{~mm})$;

$\circ$ outdoor siding (particle board, $10 \mathrm{~mm}$ ) covered with a rain shield (water-tight but vapour-permeable membrane);

- a ventilated air gap (27 mm wide);

○ a ventilated cladding $(10 \mathrm{~mm})$. 


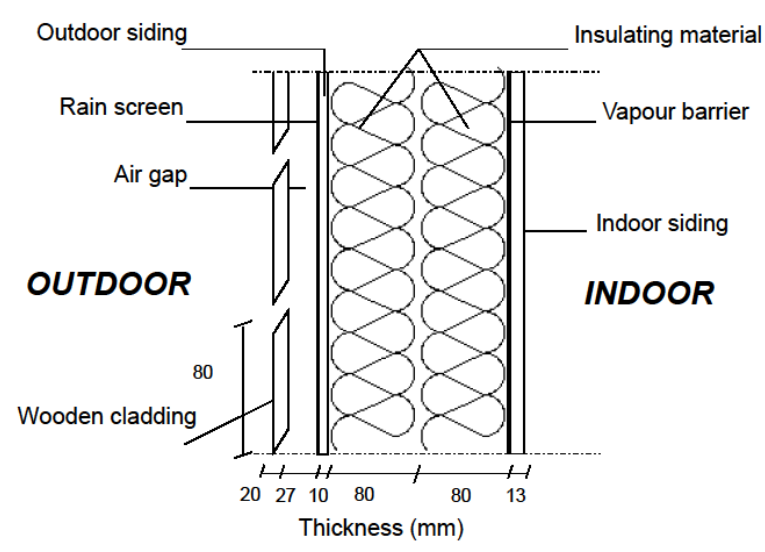

Figure 2: Scheme of the two simulated wall assemblies.

Six different wall assemblies were tested under complex temperature and humidity boundary conditions over more than 3 years. A comparison is proposed in Labat et al. (2015). The most interesting differences were observed when a classical insulating material (mineral wool) was replaced by a highly hygroscopic material (wood fibre). The influence of the vapour barrier was also reported.

In the present paper, the validating study relied on an experiment performed on a single wall assembly where wood fibre and a vapour barrier were used. In section 3, the influence of two assemblies with opposite designs in terms of vapour transfer will be analysed. The first one was vapour-tight and hardly sensitive to vapour transfer while the second one was vapouropen and included a highly hygroscopic insulating material. As a result, the influence of vapour transfer would be emphasised. These three wall assemblies are summarised in Table 1.

Table 1: Comparison of the three wall assemblies considered in this paper

\begin{tabular}{lccc}
\hline \multirow{2}{*}{ Purpose } & \multirow{2}{*}{ Validation study } & \multicolumn{2}{c}{ Numerical comparison } \\
& & Vapour-tight & Vapour-open \\
\hline Insulating material & Wood fibre & Mineral wool & Wood fibre \\
Presence of a vapour barrier & yes & yes & no \\
\hline
\end{tabular}

\subsection{Model description}

An existing simulation tool called HAM-Tools and presented by Kalagasidis et al. (2007) was 
selected to simulate coupled transfers inside the vertical walls of the building as well as transfer with indoor air. This is a software library developed originally for heat, air and moisture system analysis in building physics. It is constructed as a modular structure of standard building elements, using the graphical programming language Simulink in the Matlab environment. It is available on the Internet and open- sources, so its content can be developed by any user.

\subsubsection{Coupled heat and vapour transfers in porous media}

In a porous medium with no liquid water or air transfer, the general form of the enthalpy balance for one-dimensional cases can be written as in (2) according to Hens (2007):

$$
\begin{aligned}
& -\frac{1}{V} \cdot \frac{\partial H}{\partial t}=\operatorname{div}\left(\vec{q}_{\text {Cond }}\right)+\operatorname{div}\left(\vec{g}_{V}\left(L_{V}+C p_{V} \cdot T\right)\right) \\
& H=m_{M a t} \cdot C p_{\text {Mat }} \cdot T+m_{V} \cdot\left(L_{V}+C p_{V} \cdot T\right)
\end{aligned}
$$

Assuming there is no liquid transfer inside the walls, only vapour is considered and the mass balance can be written as:

$$
\begin{aligned}
-\frac{\partial w}{\partial t} & =\operatorname{div}\left(\vec{g}_{V}\right) \\
& =\operatorname{div}\left(-\delta_{\text {Mat }}(w) \cdot \overrightarrow{\operatorname{grad}}\left(p_{V}\right)\right)
\end{aligned}
$$

where $\mathrm{p}_{\mathrm{V}}$ is the vapour pressure defined as:

$$
p_{V}=\psi \cdot p_{S a t, V}(T)
$$

These equations were implemented in the numerical model and solved using the finite difference technique, for one dimension and with a variable time step. This model was successfully validated through a numerical comparison with other models (Kalagasidis et al. 2007; Woloszyn and Rode 2008).

\subsubsection{Material properties}

The properties of the materials were measured and are available for direct use (see Table 2). 
Thermal conductivity $\lambda_{\mathrm{D}}$ was measured with a heat flow meter apparatus, in agreement with the NF EN 12664 standard. The dependency of the thermal conductivity on the moisture content $\mathrm{w}\left(\mathrm{kg} \cdot \mathrm{m}^{-3}\right)$ is given as follows:

$$
\lambda(W)=\lambda_{D}+\lambda_{W} \cdot w
$$

The heat capacity $C p$ was measured on oven-dried samples using a micro-calorimeter $(\mu$ DSC), measuring volumes up to $1 \mathrm{~cm}^{3}$. Vapour permeability $\delta$ was measured with the cup method (dry and wet cup) according to the French NF EN ISO 12572 and 12086 standards. The samples were placed between environments at 0 and $50 \%$ of Relative Humidity (RH) for the dry cup, 50 and $94 \% \mathrm{RH}$ for the wet cup. The sorption isotherm was measured at $23^{\circ} \mathrm{C}$ and the results are presented in Figure 3. The moisture content equilibrium values were obtained with three samples and correspond to the first adsorption curve. No measurements were taken for desorption or above $95 \% \mathrm{RH}$. It is also well known that the sorption isotherm presents a hysteresis cycle (Mualem 1974; Carmeliet, De Wit, and Janssen 2005;

Kwiatkowski, Woloszyn, and Roux 2009), which is likely to impact vapour transfer.

However, its modelling is not straightforward and many authors are still using the sorption isotherm only (Osanyintola and Simonson 2006; Ramos, Delgado, and de Freitas 2010; Desta, Langmans, and Roels 2011), as was done in the present work.

Table 2: Material properties used in the simulation

\begin{tabular}{lllll}
\hline & Particle board & Gypsum board & Mineral wool & Wood fibre \\
\hline$\rho\left(\mathrm{kg} \cdot \mathrm{m}^{-3}\right)$ & 700.2 & 712.5 & 19.4 & 133.7 \\
$\lambda_{\mathrm{D}}\left(\mathrm{mW} \cdot \mathrm{m}^{-1} \cdot \mathrm{K}^{-1}\right)$ & 106.7 & 190 & 32 & 37.2 \\
$\lambda_{\mathrm{W}}\left(\mathrm{mW} \cdot \mathrm{m}^{-1} \cdot \mathrm{K}^{-1} \cdot \mathrm{kg}^{-1} \cdot \mathrm{m}^{3}\right)$ & 0.13 & 1.67 & 0.00 & 1.00 \\
$\mathrm{Cp}\left(\mathrm{J} \cdot \mathrm{kg}^{-1} \cdot \mathrm{K}^{-1}\right)$ & 1270 & 1010 & 760 & 1200 \\
$\delta$-dry cup $\left(10^{-12} \mathrm{~s}\right)$ & 2.11 & 21.7 & 167 & 5.41 \\
$\delta$-wet cup $\left(10^{-12} \mathrm{~s}\right)$ & 2.79 & 29.8 & 167 & 5.88 \\
\hline
\end{tabular}




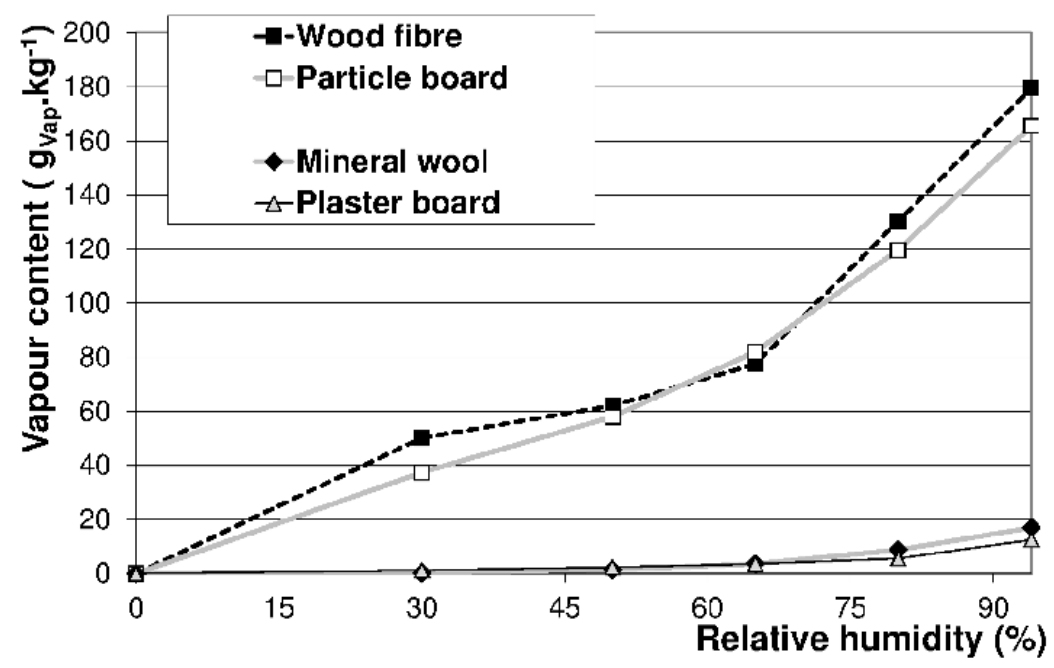

Figure 3: Sorption isotherms measured for each material.

\subsubsection{Simulating transfers in the ventilated cavity}

During earlier work (Labat et al. 2012), a strong two-dimensional effect was shown to be induced by the wooden cladding and the air gap. To include this phenomenon, the abovementioned wall model was enhanced to include the modelling of coupled heat and air transfer in the ventilated cavity. The general pattern is presented in Figure 4 and consists of dividing each single vertical wall into seven parts. Coupled transfers were still modelled from a onedimensional point of view in solid parts. In the ventilated cavity, however, the vertical effect was modelled. Air transfer was based on a semi-empirical correlation and heat transfer was described using general results from the literature, as presented in Labat et al. (2012), where more details can be found. The results were compared to measurements taken under harsh conditions for both the eastern and western walls. Computed heat fluxes were integrated on a 24-h basis and found to be accurate within $8 \%$ throughout the year. Vapour transfers in the ventilated cavity were modelled using a single value for the convective surface mass transfer coefficients (see also section 2.2.4 below). 


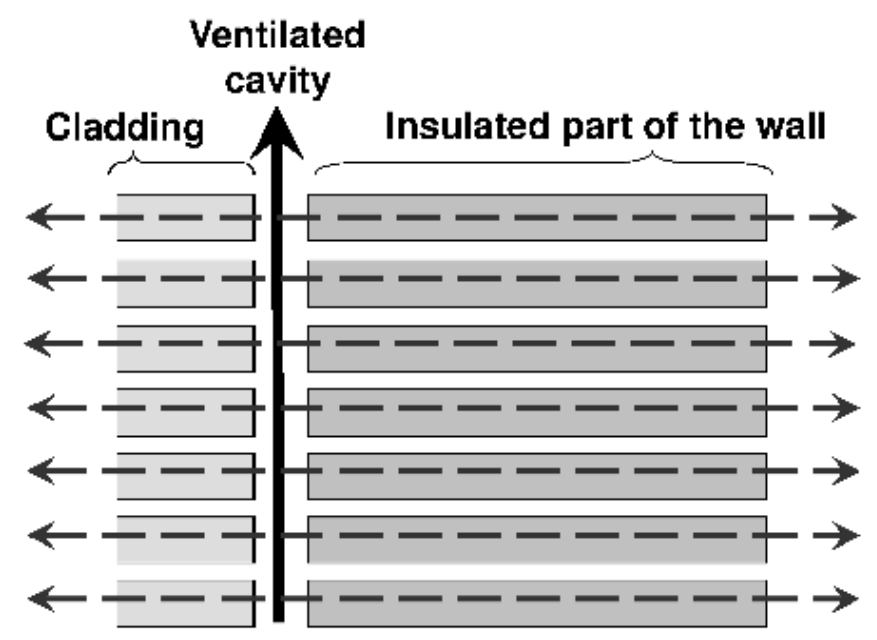

Figure 4: Modelling scheme of the two-dimensional effect induced by the ventilated cavity

\subsubsection{General considerations}

During the experiments, six Vaisala HUMICHIP 17204HM thermo-hygrometers were installed between each layer and its neighbour to monitor the temperature and the relative humidity, as shown in Figure 5. The vertical walls were meshed with 19 nodes: ten for each siding and nine for the insulating material. For a precise comparison with measurements, the nodes located close to the sensor locations were sized down to $0.5 \mathrm{~mm}$ in the siding and 1.5 $\mathrm{mm}$ in the insulating material. The solution was found to be independent of the mesh chosen by comparing the results obtained with finer meshes.

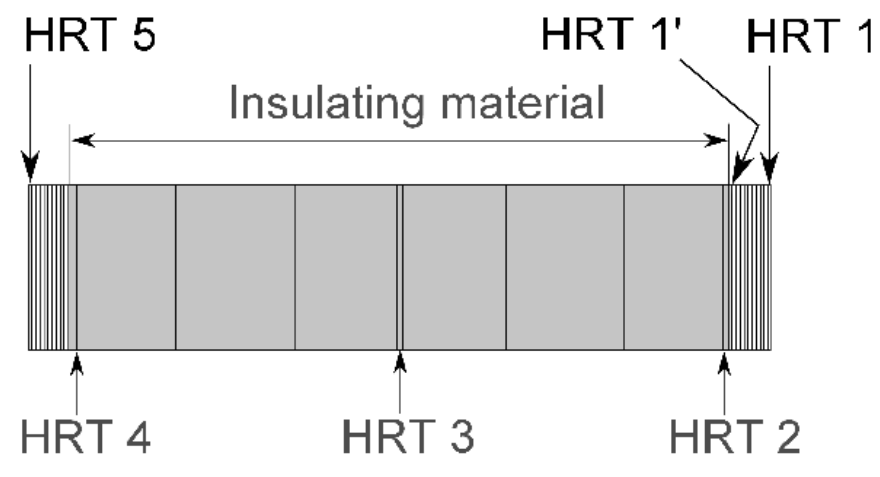

Figure 5 : Mesh applied to the insulated part of the vertical wall and sensor location 
As stated in Qin et al. (2011), the convective surface heat transfer coefficient is variable, but a constant value is usually preferred in simulations performed at room scale. In this study, constant values were used for heat and mass transfer coefficients $\left(h_{I n}, h_{m, I n}\right.$ and $\left.h_{m, \text { Out }}\right)$ and the indoor irradiative coefficient $\left(\mathrm{h}_{\text {Irr,In }}\right)$. They were fitted by using a 3-month experiment under stable indoor conditions (measurements not presented here) and are consistent with the values used in the literature. The results are presented below:

- $\mathrm{h}_{\mathrm{In}}=6 \mathrm{~W} \cdot \mathrm{m}^{-2} \cdot \mathrm{K}^{-1}$

- $\mathrm{h}_{\mathrm{Irr}, \mathrm{In}}=4 \mathrm{~W} \cdot \mathrm{m}^{-2} \cdot \mathrm{K}^{-1}$

- $\mathrm{h}_{\mathrm{m}, \mathrm{In}}=1 \cdot 10^{-8} \mathrm{~kg} \cdot \mathrm{m}^{-2} \cdot \mathrm{s}^{-1} \cdot \mathrm{Pa}^{-1}$;

- $\mathrm{h}_{\mathrm{m}, \text { Out }}=1 \cdot 10^{-8} \mathrm{~kg} \cdot \mathrm{m}^{-2} \cdot \mathrm{s}^{-1} \cdot \mathrm{Pa}^{-1}$.

A classical single-node pressure model was previously selected to estimate the global air change rate under natural conditions. Experimental measurements, based on air permeability and the tracer gas techniques, were used to fit numerically obtained wind and thermal coefficient values (Labat, Woloszyn, Garnier, and Roux 2013). The overall air change rate computed was estimated to be accurate within $23 \%$. It was also shown that the model represented the best measurements for average outdoor conditions, while greater differences occurred when the wind speed was higher than $3 \mathrm{~m} \cdot \mathrm{s}^{-1}$.

\subsection{Brief description of the validation study}

In a previous study (Labat, Woloszyn, Garnier, Piot, et al. 2013), coupled transfers were simulated altogether. The modelling included the vertical walls and the ventilated cavities, the indoor volume and the air change rate. Transfers across the floor, the ceiling, the door and the structure were not simulated because they had not yet been validated. However, vapour transfer in all indoor siding, including the horizontal surfaces and the door, were taken into account. The results are briefly summarised below. 
An experimental campaign conducted over 15 days in February 2012 was selected. For 3 months preceding the experiment and during the period of interest here, the indoor temperature was maintained at $20 \pm 1^{\circ} \mathrm{C}$. Then, vapour was generated by means of a cold mist generator for approximately $28 \mathrm{~h}$, from $06 / 02 / 2012$ to $07 / 02 / 2012$. The exact production rate was measured by weighing the generator. It appeared to be constant (close to $200 \mathrm{~g} \cdot \mathrm{h}^{-1}$ ); consequently, the total amount of vapour generated reached almost $6 \mathrm{~kg}$. Finally, the ventilation system remained turned off during the whole experiment, yet air leakages still occurred. The outdoor conditions were used as boundary conditions. Vapour production was simulated according to a mass measurement of the vapour generator and heat production was adjusted in a preliminary calculation in order to fit the measured indoor temperature. Indoor air volume was modelled as a single node. Its temperature and humidity were not fixed but computed using heat and mass balances, including transfers with indoor sidings, the production of heat and vapour, and the impact of the air change rate. These balances indicated how accurate the model was at room scale.

Temperature measurements in the walls were plotted against the simulation results. The greatest differences were observed on the southern side, and the results are presented at three different depths in Figure 6. On both sides of the indoor siding (T1 and T3), the difference between the measurements and the simulation results was lower than the measurement uncertainty $\left( \pm 0.8^{\circ} \mathrm{C}\right)$. This was to be expected as indoor temperature was fixed in the model. Between the insulating material and the outdoor siding (T5), however, greater differences occurred. Specifically, they exceeded $3^{\circ} \mathrm{C}$ four times. For other wall orientations, this marked difference was never observed. This is a direct consequence of the ventilated cavity modelling, which was based on measurements made on the eastern and western façades. The southern ventilated cavity geometry was noticeably different (it was smaller and the roof overhang was much longer). Therefore the ventilated cavity behaviour could differ 
significantly. Nevertheless, temperature differences were occasional and did not greatly affect the overall energy behaviour. This can be seen in Figure 7, where heat flux measurements were integrated over $24 \mathrm{~h}$ and found to be within $3 \%$ of simulation results.

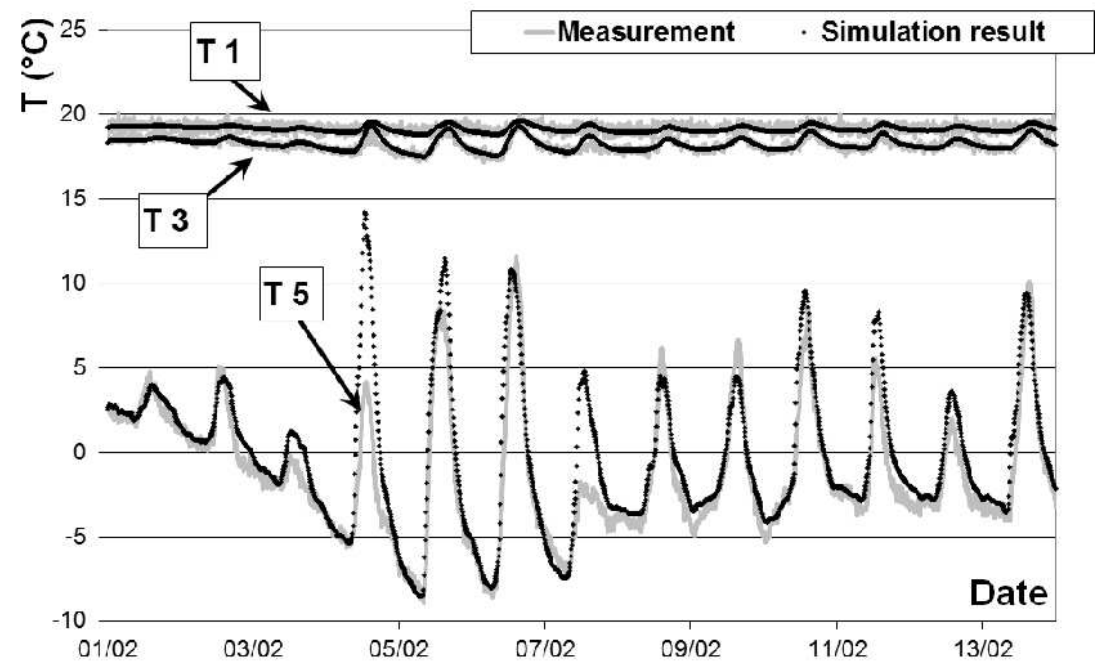

Figure 6: Temperature measurements in the southern wall and simulation results

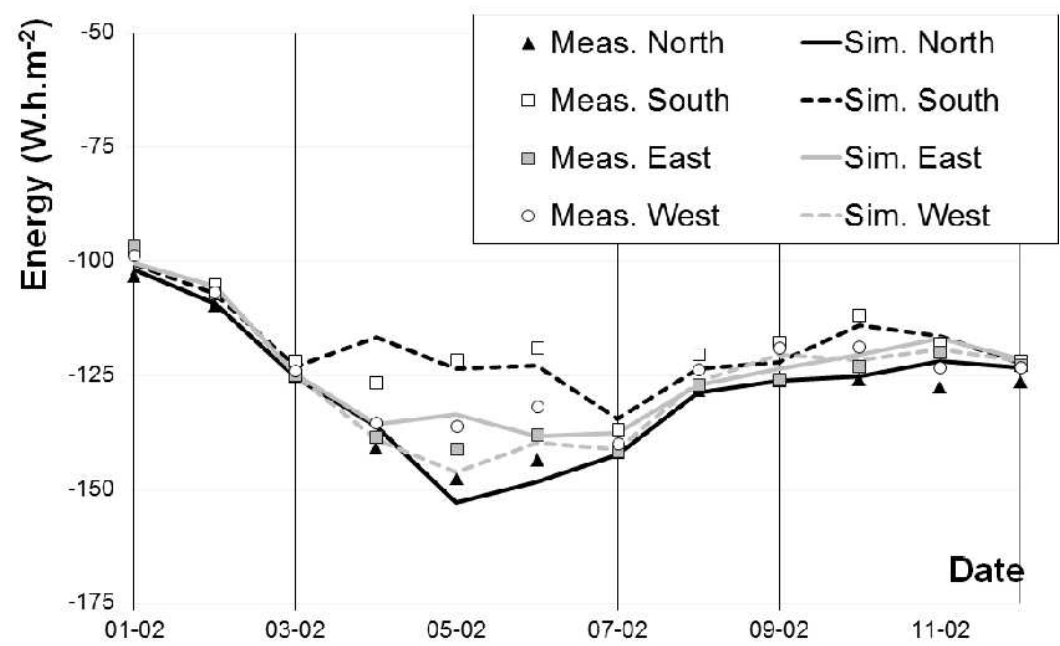

Figure 7: Comparison of heat flux measurement integrated over an entire day with simulation results for each orientation

It can be tricky to study relative humidity measurements directly because they depend 
substantially on temperature. Therefore, some authors prefer to consider vapour pressure, which is the potential governing vapour transfer (Carmeliet and Derome 2012; Piot et al. 2011). Alternatively, absolute humidity defined as the mass ratio of water in dry air and derived from vapour pressure, as shown in (5), can be used. It was selected in this paper for the comparison with the numerical results.

$$
A H=\frac{r_{V}}{r_{D r y}} \cdot \frac{p_{V}(\psi, T)}{p_{T o t}-p_{V}(\psi, T)}
$$

Absolute humidity measurements are plotted versus the simulation results in Figure 8 for the same positions as used for temperature measurements in Figure 6. First, it should be underlined that the model behaves satisfactorily, since computed values of indoor absolute humidity (AH 1) follow the measurements closely during the whole experiment. This means that vapour transfers at room scale were suitably identified and described. Greater differences were observed at the end of the experiment because the accuracy of the air change rate calculation was lower for wind velocities greater than $3.0 \mathrm{~m} . \mathrm{s}^{-1}$ (the average velocity was 3.8 $\mathrm{m} . \mathrm{s}^{-1}$ during this experiment).

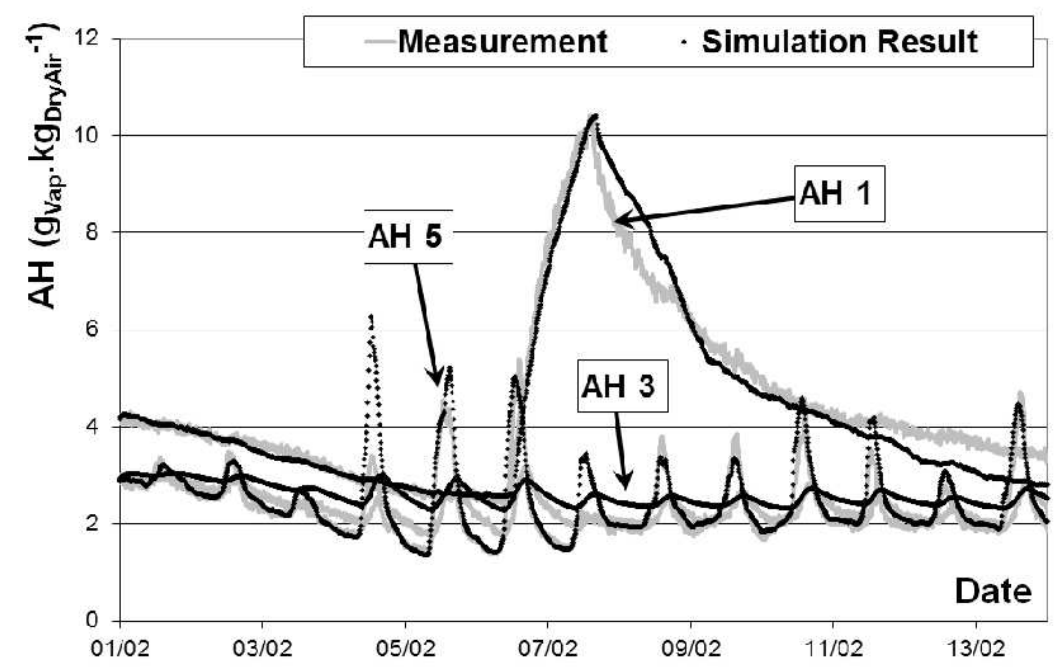

Figure 8: Absolute humidity measurements in the southern wall and simulation results 
Second, vapour transfer in the insulating material was not influenced by indoor climate because of the vapour barrier. On the other hand, temperature variations on the outdoor siding were great enough to prompt vapour transfer. This phenomenon is known as sun-driven vapour transfer (Carmeliet and Derome 2012; Piot et al. 2011). In consequence, differences in absolute humidity were the greatest as soon as the temperature was poorly estimated (04/02, 07/02). This resulted in an insignificant bias in the long term.

Therefore, it can be concluded that the model represents the overall behaviour of both elements: wall and indoor air satisfactorily. This encourages confidence in the heat and vapour balance at room scale.

\section{Description of the simulated building and the input parameters}

This section discusses the selection of the input parameters, namely the geometry of the simulated building, the boundary conditions, the initial conditions and the simulation duration. Finally, specific attention will be paid to the modelling of moisture production.

\subsection{Simulated building and selection of two wall assemblies}

Since the numerical model calibration was based on measurements obtained with this set-up and in order to stay within its scope of validity, the simulated building was similar to the experimental house. Therefore, it was representative of a small apartment that would be suitable for a single student:

- It was a $5 \mathrm{~m} \times 5 \mathrm{~m} \times 2.5 \mathrm{~m}$ single-room building. Because of its small size, the impact of moisture production should be considerable.

- The horizontal walls were assumed to be adiabatic, representative of similar apartments being located above and below. 
- Vapour transfer with the floor was not taken into account: this corresponds to the use of linoleum or tiles as floor covering. On the other hand, the ceiling was covered with a 12-mm-thick gypsum board which could exchange vapour with the indoor air.

- Each of the four vertical walls was oriented towards a cardinal direction: no doors or windows were simulated. Consequently, simulated vertical walls were exactly the same for all orientations. The structure of the experimental building was made of vertical studs, which were not simulated here. Therefore, the simulated vertical walls were uniform over their entire surface.

- Two different vertical wall assemblies (vapour-tight and vapour-open) were considered as presented in Table 1.

The use of a vapour barrier is questionable because it is rather fragile (it is composed of a simple polyethylene sheet). Moreover, its efficiency depends considerably on the workmanship of the construction. Therefore, it is worth considering an alternative assembly with no vapour barrier, which has already been suggested (Karagiozis and Salonvaara 2001; Carey J. Simonson, Salonvaara, and Ojanen 2001; Latif et al. 2015). The resulting wall assembly should be more vapour-permeable and the vapour transfer effect should be greater.

\subsection{Simulation duration, outdoor and initial conditions}

Moisture storage in hygroscopic material (wood fibre, particle board) occurs slowly compared to heat transfer. Therefore, it is necessary to perform simulations over a few months at least to observe significant variations. For example, simulations of periods longer than 1 year were considered in studies focusing on durability (Isaksson et al., 2010; Van den Bulcke et al., 2011). However, considering an entire year may cause additional problems, mostly in summer. Here, the simulated building has low thermal inertia and is exposed to outdoor 
conditions, including direct solar irradiance. Significant heat transfers may occur and lead to considerable discomfort and unrealistic cases. In fact, summer comfort depends mostly on the use of dedicated devices (cooling systems) and the inhabitants' behaviour (opening the window). Although opening windows is simple, its impact on the air change rate is hard to predict (Yuguo Li and Delsante, 2001). Also, it significantly impacts indoor relative humidity, and leads to greater uncertainties in this simulation work. For these reasons, in the present study, a 1-year period was simulated, but the period from June to September was not studied.

Naturally, the outdoor conditions influence the coupled transfers in the envelope. However, it is hardly feasible to consider the entire climate range. This is why most studies use local weather data. Djebbar, van Reenen, and Kumaran (2001) developed a method to select outdoor conditions suitable for the study of moisture storage. The idea was to determine the year in which the harshest conditions occurred, which required data collection over several years. Here, the TMY (typical meteorological year) file from Grenoble, France, was used. A quick comparison with the outdoor conditions used for the calibration of the numerical tool showed that the temperature and humidity were within the same range. Therefore, the numerical model was still within its validation range. Finally, hourly defined weather conditions were interpolated every $10 \mathrm{~min}$.

Initial conditions should be set so that they have no impact on the final results. Here, the most sensitive parameter was the initial moisture content within the walls. An efficient way to limit its influence was to start the simulation several months before the study period. Thus, the simulation was started on $1^{\text {st }}$ June and moisture production was started on $1^{\text {st }}$ September. To set realistic initial conditions, the temperature and relative humidity measured in the experimental house in the different layers of the wall assembly in June 2009 were used as initial conditions. Profiles are presented in Figure 9, where the x-axis represents the wall depths from outdoors to indoors. According to the measurements of six thermo-hygrometers 
located indoors during the same period, indoor air was set at $26^{\circ} \mathrm{C}$ and $46 \%$ relative humidity.

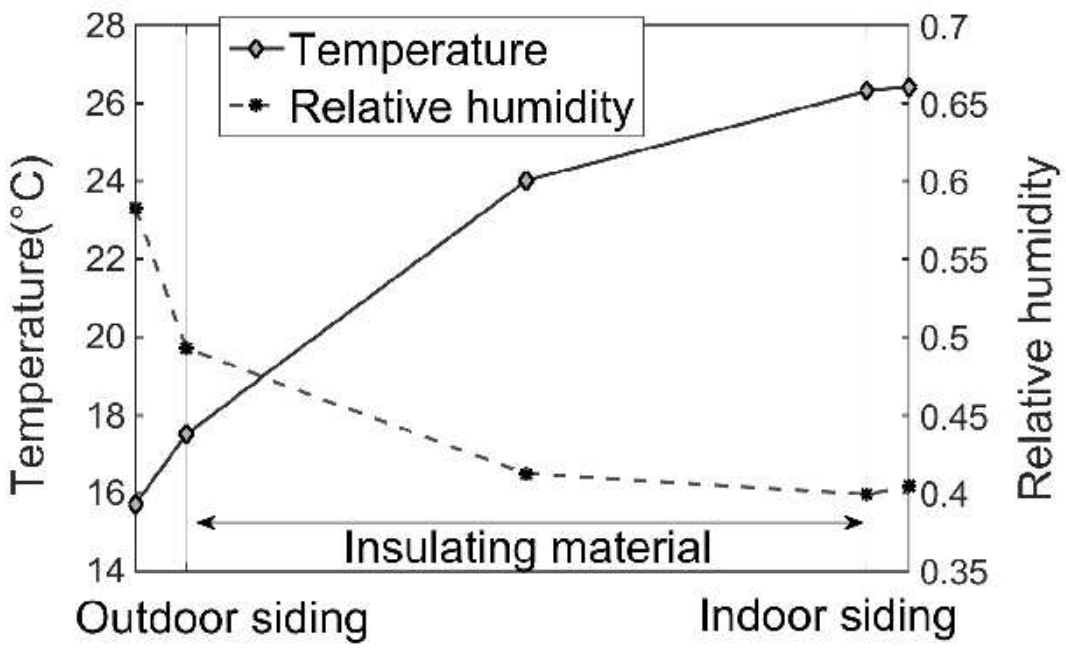

Figure 9: Initial temperature and relative humidity values at different depths of the vertical walls

\subsection{Heating and ventilating systems}

In this study, indoor conditions were defined with three parameters:

- The heating system;

- The air change rate;

- The moisture production.

Excluding studies focusing on specific systems, such as (Steeman, Janssens, and De Paepe 2009), the heating and cooling systems have often been simplified because they seek to maintain the indoor temperature constant. Here, no cooling system was simulated and, for the heating system, the threshold value for indoor temperature was set at $20^{\circ} \mathrm{C}$. In accordance with the purpose of our study, however, the ventilation system and the moisture production needed to be defined more carefully. According to Laverge, Pattyn, and Janssens (2013), a constant air change rate (ach) of $0.5\left(32.5 \mathrm{~m}^{3} \cdot \mathrm{h}^{-1}\right.$ here $)$ is representative of European 
regulation codes. Moreover, it is in agreement with the French code (Arrêté Du 24 Mars 1982). Therefore, a first ventilation system was defined with these specifications, representative of a common constant ventilation rate system. The second system of interest was an RHS ventilation system, which was developed to manage the moisture balance of indoor air. Comparing the two systems would highlight the potential benefits of this device. To our knowledge, no dedicated regulation code exists for such systems but an example is given in the French code. However, better results were obtained (Woloszyn et al., 2009) by modifying the RHS ventilation scheme, namely the threshold values. Different schemes were proposed depending on the climate and on whether or not moisture buffering materials were present (Figure 10). An interesting point is that a $45 \%$ indoor relative humidity was targeted for all cases: only the lower and upper thresholds were different. This targeted value corresponds to the comfort criteria defined by Wolkoff and Kjærgaard (2007) and is given in the European standard EN 1521:2007.

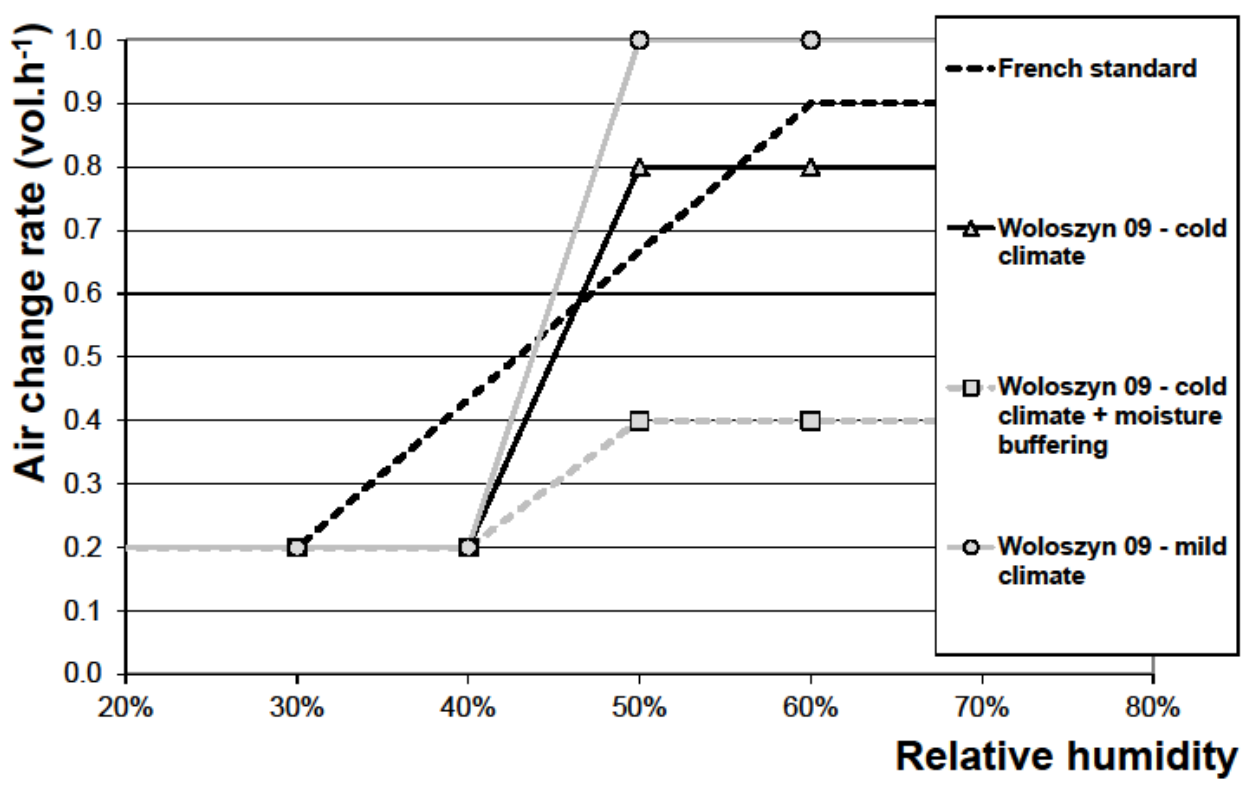

Figure 10: Examples of RHS ventilation schemes

In the present study, we decided to use the intermediate ventilation scheme presented by 
Woloszyn et al. (2009), which corresponds to a cold climate (it varies from 0.2 to 0.8 ach when indoor relative humidity increases from 40 to $50 \%$ ). The average value is [0.5ach; $45 \%$ $\mathrm{RH}]$, which corresponds to the requirements of the standard and this ventilation scheme is very close to the one proposed by the French standard. Therefore, it is appropriate for both the climate and the wall assemblies considered.

The air infiltration rates measured in the test house (Labat, Woloszyn, Garnier, and Roux 2013) were significantly lower than the recommended air change rate values mentioned in the European standards. Therefore, it was presumed that the air infiltration should not be significant if a mechanical ventilation system was used. Consequently, the imposed air change rate was simulated and air leakages were not taken into account. Finally, the value of the air change rate was calculated for each time step, based on the computed indoor relative humidity value and the ventilation scheme.

\subsection{Moisture production scenarios}

As stated in Section 1, the moisture production schedule is often simulated by defining a single cycle, which is repeated. The objective here was to define a schedule for the entire duration of the simulation (9 months), with no repeated cycles. Therefore, an occupancy schedule was first defined by considering various moisture-producing activities. Moisture production rates and frequencies will be presented for different indoor activities. Finally, the average moisture production is compared to values reported in the literature.

\subsubsection{Occupancy schedule}

Based on a time-use survey obtained from more than 3000 Belgian households, 7 discrete occupancy profiles were determined by Aerts et al. (2013). Very different occupancy profiles were obtained depending on the household size, the age, employment and income of its 
members. Weekdays were distinguished from weekends. These were the main contributions, and the authors concluded that combining such discrete profiles with a probabilistic approach would be valuable for energy modelling. In the present work, we adapt their results to the case of the moisture production schedule. This was done by selecting a profile corresponding to a student or a young working individual, in accordance with the type of dwelling investigated.

A single inhabitant was assumed to live in the dwelling, so two cases were possible depending on whether or not the inhabitant was present. The occupancy schedule was defined from $1^{\text {st }}$ September to $1^{\text {st }}$ June with a 10-min time step. Public holidays were not taken into account, but the inhabitant was assumed to leave the dwelling around Christmas (from 24 December to 2 January). Except for this period, average worker behaviour was assumed and can be summarised as follows:

- The inhabitant works 5 days in a row. Therefore, two different occupancy schedules were considered: one for working days and the other for days off.

- The inhabitant may spend the weekend away from the dwelling (the corresponding probability is 0.2 ). In this case, there was no occupancy schedule from Friday morning to Sunday evening. Except for this case, the inhabitant always slept at home.

- The occupancy schedule was based on a typical schedule (going to work at 7.30, returning home at 18.00 , etc.). It was designed to represent rather stay-at-home behaviour, thus favouring moisture production. To be more realistic, these typical hours were combined with a standard deviation and a normal distribution was assumed. For example, the inhabitant was assumed to go to work at $7.00 \pm 30 \mathrm{~min}$. A similar approach has been used by other authors (Salonvaara, Karagiozis, and Holm 2001; Laverge, Pattyn, and Janssens 2013). Details are presented in Table 3 and the presence probability is plotted in Figure 11. 
Table 3: Values used to define the occupancy schedule

\begin{tabular}{llll}
\hline Period & Action & Probability & Time \\
\hline \multirow{2}{*}{ Leaving home } & 1.0 & $07.00 \pm 0.30^{(1)}$ \\
Working Day & Coming back for lunch & 0.2 & $12.00 \pm 0.10$ \\
& & & $13.00 \pm 0.10^{(2)}$ \\
& Coming back after work & 0.8 & $18.30 \pm 0.30$ \\
& Coming back later in the evening & 0.2 & $21.30 \pm 1.00$ \\
\hline \multirow{2}{*}{ Leaving home in the morning } & 0.2 & $09.30 \pm 0.30$ \\
& & & $11.30 \pm 0.30$ \\
& Leaving home for lunch & 0.1 & $11.30 \pm 0.30$ \\
& & & $14.00 \pm 0.30$ \\
Lay-off & Leaving home in the afternoon & 0.7 & $14.00 \pm 0.30$ \\
& & & $17.30 \pm 1.00$ \\
& Leaving home in the evening & 0.3 & $20.30 \pm 0.30$ \\
\hline
\end{tabular}

(1) Value used as the standard deviation in the definition of the normal distribution.

(2) This second line contains the time the inhabitant would leave home after lunch.

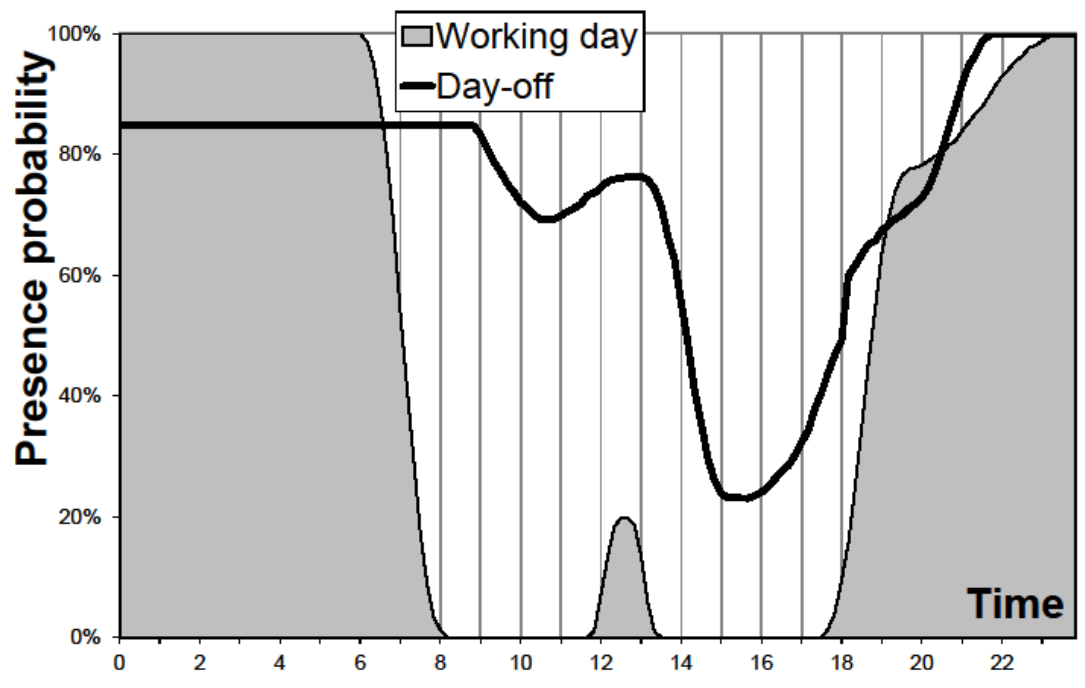

Figure 11: Probability density functions of inhabitant being present in the dwelling for both working days and days off.

\subsubsection{Moisture production}

Multiple moisture production sources have been detailed by Pär Johansson, Pallin, and 
Shahriari (2010). The figures presented in their study are used here, but fewer activities were considered:

- Personal grooming: only showering was considered. No detailed data were available for other washing activities (use of a washbasin, toilets, etc.). Bathing, saunas and whirlpools were excluded.

- Cooking: the inhabitant was assumed to have three meals a day, every day. The cooking activity depended on the occupancy schedule (e.g. the cooking activity for lunch was considered only if the inhabitant was at home at noon). Different production rates were assumed for each meal.

- Dishwashing: because of the small size of the dwelling, no dishwasher was considered. Consequently, the inhabitant was assumed to wash dishes by hand.

- Washing: drying clothes results in high moisture production, especially if a dryer is not used. Here, data collected from the unvented drying activity were used.

- Breathing: 26 different activities are listed by Johansson et al. 2010), with various production rates. Here only three cases were considered (sleep, rest and busy). Four parameters were used to model each activity and are presented in Appendix 1 and Figure 12. Although highly detailed values were provided by (Pär Johansson, Pallin, and Shahriari 2010), a few were modified:

- Cooking dinner: the highest probability was moved from 17.00 to 19.00. This is more consistent with the occupancy schedule and much more representative of French habits.

- No durations were given for the cooking activities: the values used here were all arbitrarily determined. 
- The initial frequency of hand dishwashing (every 2 days) was increased to every day because of the small size of the dwelling and the high occurrence of the cooking activity.

- The clothes washing activity was largely described by (Pär Johansson, Pallin, and Shahriari 2010), especially concerning the different means by which clothes could be dried. The probability density function was not given, so figures given for the floor mopping activity were used instead. The frequency seemed to be too high (up to nine times a week for a single person) and was decreased to three times a week. This high value could result from using a washing machine with a low load capacity ( $3 \mathrm{~kg}$ ).

However, machines with a higher capacity $(5 \mathrm{~kg})$ seem much more common, at least in France. Moreover, a 5-kg load is considered in IEA Annex XIV (1991). This was adapted so that an average of $8.5 \mathrm{~kg}$ of clothes washed per week was simulated.

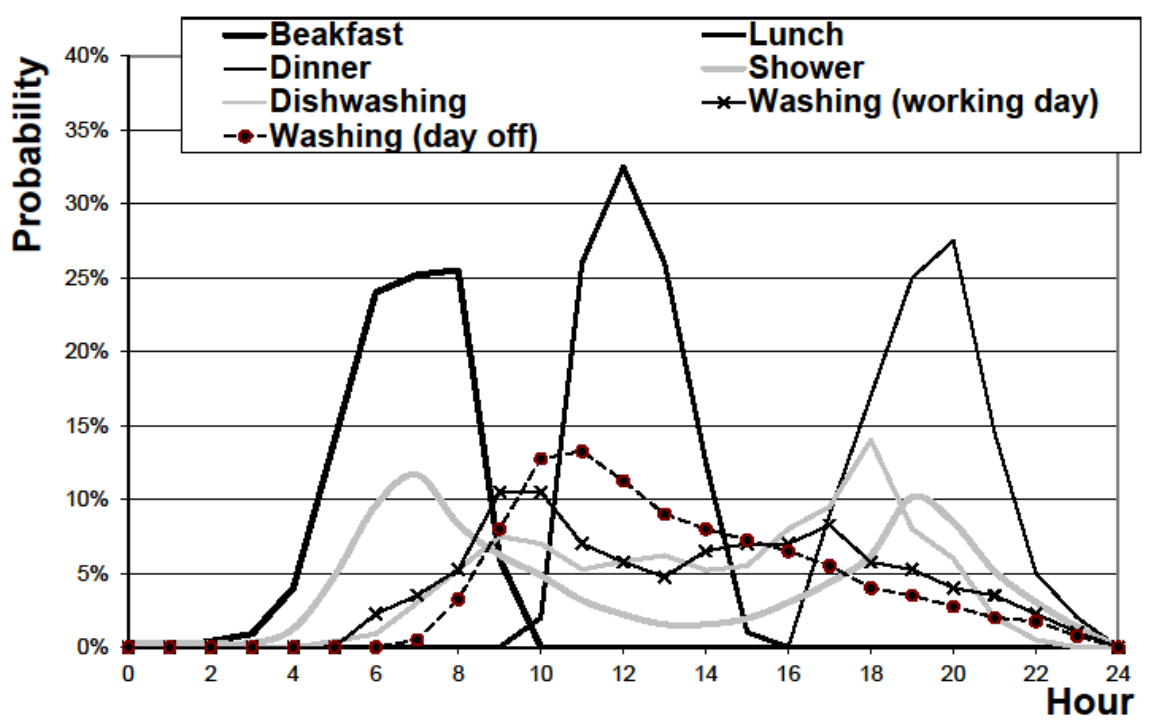

Figure 12: Probability density functions of starting a moisture generating activity

\subsubsection{Comparison with values used in the literature}

The values presented in the previous section were used to compute the moisture production over 9 months with Matlab, and this was repeated 1000 times (this calculation was 
independent of the modelling of the building). The average moisture release was $721 \mathrm{~kg}$ per year, which corresponds to an average production rate of $83 \mathrm{~g} \cdot \mathrm{h}^{-1}$. Of course, the production rate was not uniform and a higher instantaneous rate could be reached (up to $2000 \mathrm{~g} \cdot \mathrm{h}^{-1}$ ), as exemplified in Figure 13.

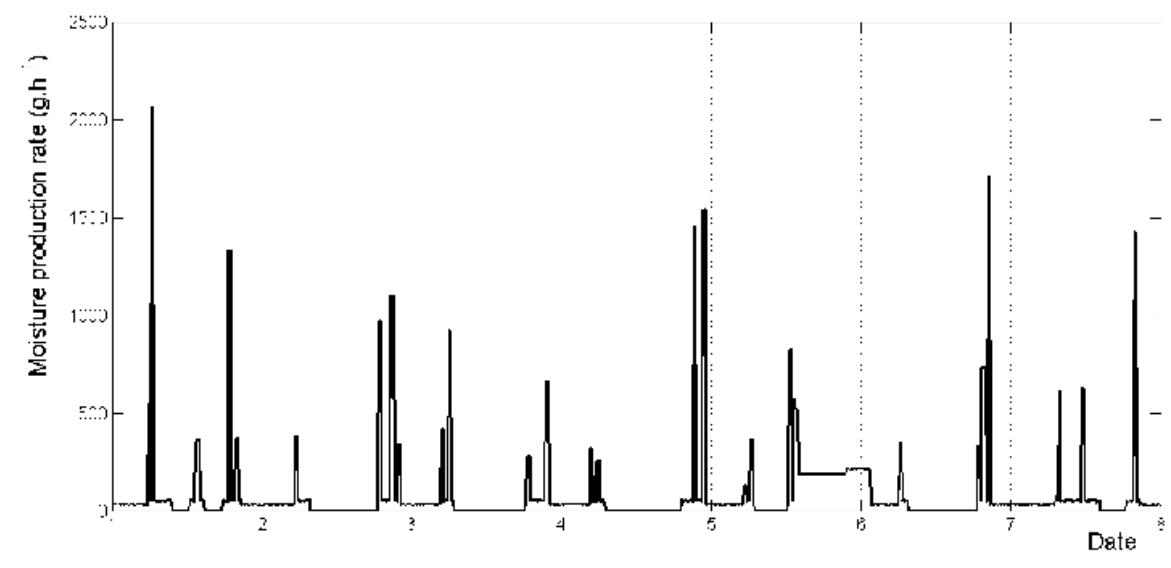

Figure 13: Moisture production, 1-7 September.

The values of the input parameters used in the studies reviewed are summarised in Appendix 2. A standardised moisture production rate was computed using the indoor volume and considering the $24-\mathrm{h}$ averaged rate for a single inhabitant. A similar normalisation has been proposed by others ( $\mathrm{Lu}, 2003$; Hameury, 2005) to take the indoor air volume into account. It helps to picture the relative influence of moisture sources on the indoor air balance, although other factors have influence (namely the air change rate, the intended use of the building, etc.). The standardised production rate was $1.32 \mathrm{~g} \cdot \mathrm{h}^{-1} \cdot \mathrm{m}^{-3}$, which is very close to the values used in other works (Hameury, 2005; Janssens and De Paepe, 2005; Woloszyn et al., 2009) $\left(1.18,1.28\right.$ and $1.69 \mathrm{~g} \cdot \mathrm{h}^{-1} \cdot \mathrm{m}^{-3}$ respectively; see Appendix 2). It is interesting to note that the lowest production rates were used with studies in which the buffering effect was not targeted (Karagiozis and Salonvaara 2001) $\left(0.09 \mathrm{~g} \cdot \mathrm{h}^{-1} \cdot \mathrm{m}^{-3}\right)$ or if the floor area was greater than $100 \mathrm{~m}^{2}$ (TenWolde and Walker 2001; Walker and Sherman 2007) $\left(<0.4 \mathrm{~g} \cdot \mathrm{h}^{-1} \cdot \mathrm{m}^{-3}\right)$. Therefore, it appears that this modelling of the moisture production is consistent with other results reported 
in the literature and fits the purpose of this study. Finally, a moisture production scenario having an average value close to $1.32 \mathrm{~g} \cdot \mathrm{h}^{-1} \cdot \mathrm{m}^{-3}$ was selected. This scenario was used as an input parameter in the simulation tool for the four cases (it was not recalculated, so the production rate was exactly the same for each case).

\section{Simulations and analysis of the results}

The numerical model for heat and moisture simulations at room scale was set up with the occupancy and the moisture production rate modelled as proposed in section 3.4 . The ventilation rates were modelled as discussed in section 3.3. As mentioned above, the measured hygrothermal properties of the materials were used, and 1-year simulations were performed.

The numerical model was run four times to compare four cases, depending on the wall assembly and the ventilation system:

1. Vapour-tight wall assembly (mineral wool + vapour barrier) with a constant ventilation rate;

2. Vapour-tight wall assembly with an RHS ventilation system;

3. Vapour-open wall assembly (wood fibre and no vapour barrier) with a constant ventilation rate;

4. Vapour-open wall assembly with an RHS ventilation system.

For the four cases, the other boundary conditions (moisture production, initial conditions, etc.) were exactly the same. The resulting analysis is presented in two sections, one for each time scale: 
- At the yearly scale: indoor relative humidity distribution, moisture content distribution in the materials and durability are presented.

- At the monthly scale: the seasonal variations of the air change rate, vapour transfer with the walls and the heating power are analysed.

Finally, the most important results are summarised in a third section and the influence of the moisture production schedule is specifically discussed.

\subsection{Comparison at the yearly scale}

\subsubsection{Indoor relative humidity}

The indoor relative humidity results from the combination of moisture production, vapour transfer with the walls and air change rate. It impacts the air quality and therefore the comfort of the inhabitant, as underlined by Wolkoff and Kjærgaard (2007) who targeted values for indoor relative humidity ranging from 40 to $50 \%$. No general conclusions could be drawn for dry air $(<40 \%)$. In contrast, there was evidence of the negative impact of exposure to humidity greater than $60 \%$. Here, the values computed with the simulation tool were used to calculate the distribution presented in Figure 14. For case no. 1 (vapour-tight wall assembly, constant ventilation), the shape of the distribution is rather regular, meaning that no peak was observed; $24 \%$ of the values were within the $[40 \% ; 50 \% \mathrm{RH}]$ range. No values lower than $15 \% \mathrm{RH}$ were observed, and $32 \%$ of the values were higher than $60 \% \mathrm{RH}$.

The use of RHS ventilation had the most obvious impact on indoor humidity. First, the distribution spread was lower, especially for the highest values: indoor humidity was lower than $60 \%$ RH during $20 \%$ of the year when RHS ventilation was used (32\% with constant ventilation). Second, the targeted comfort range $[40 ; 50 \% \mathrm{RH}]$ was obtained more frequently ( $42 \%$ of the year versus $24 \%$ with a constant rate). This was a direct consequence of the 
ventilation scheme (see Figure 10), which targets this range. The use of a vapour-open wall instead of a vapour-tight wall had a similar impact on indoor humidity but this impact was less than when RHS ventilation was used. Comfort was increased by $3 \%$ and the occurrence of high humidity was decreased by $4 \%$. When combining RHS ventilation with a vapour-open wall, it was observed that the indoor climate was only slightly affected by the vapour-open wall. This means the ventilation system had the highest impact on indoor humidity.

In conclusion, it was demonstrated that the use of RHS ventilation had the most sizeable impact on indoor comfort. The use of a vapour-open configuration and highly hygroscopic insulation material had a lesser influence but comfort was also improved.

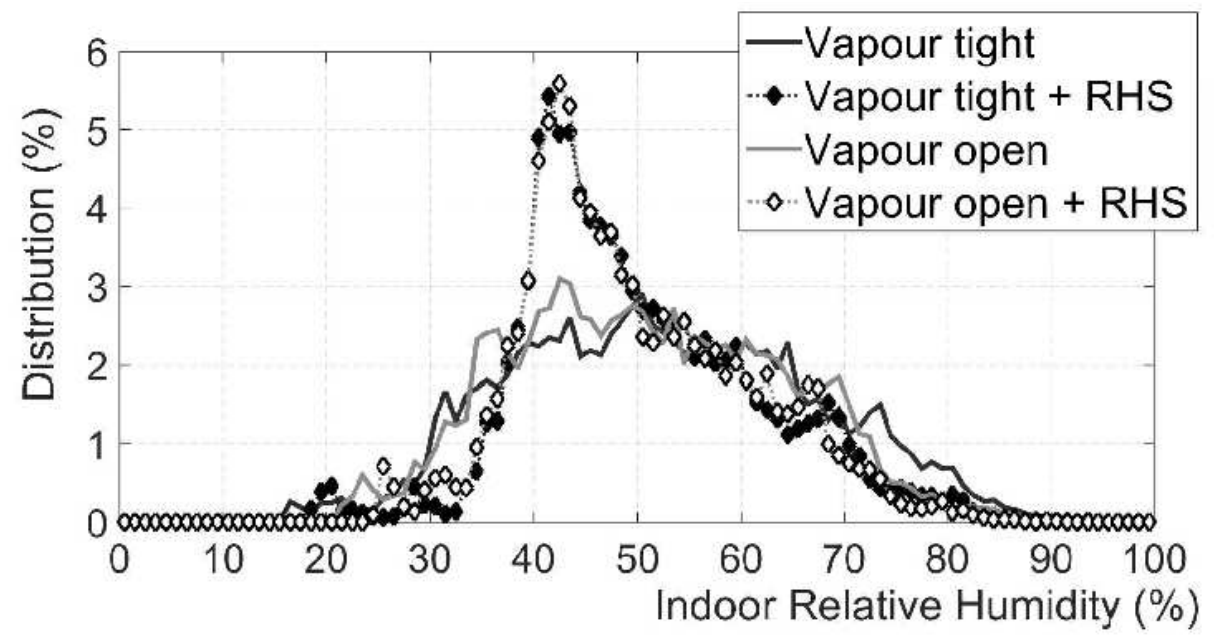

Figure 14: Distribution of indoor relative humidity for the four cases simulated

\subsubsection{Moisture content in the vertical walls}

The moisture content was determined using the relative humidity computed for each node of the vertical walls and the measured sorption isotherms (see Figure 3). The values obtained for the same materials at each depth and for each wall orientation were summed so as to estimate the total mass of moisture contained in the different materials (expressed in $\mathrm{kg}$ ), which gave a general idea of how the moisture balance behaved. The distributions are presented in Figure 
15 to Figure 18.

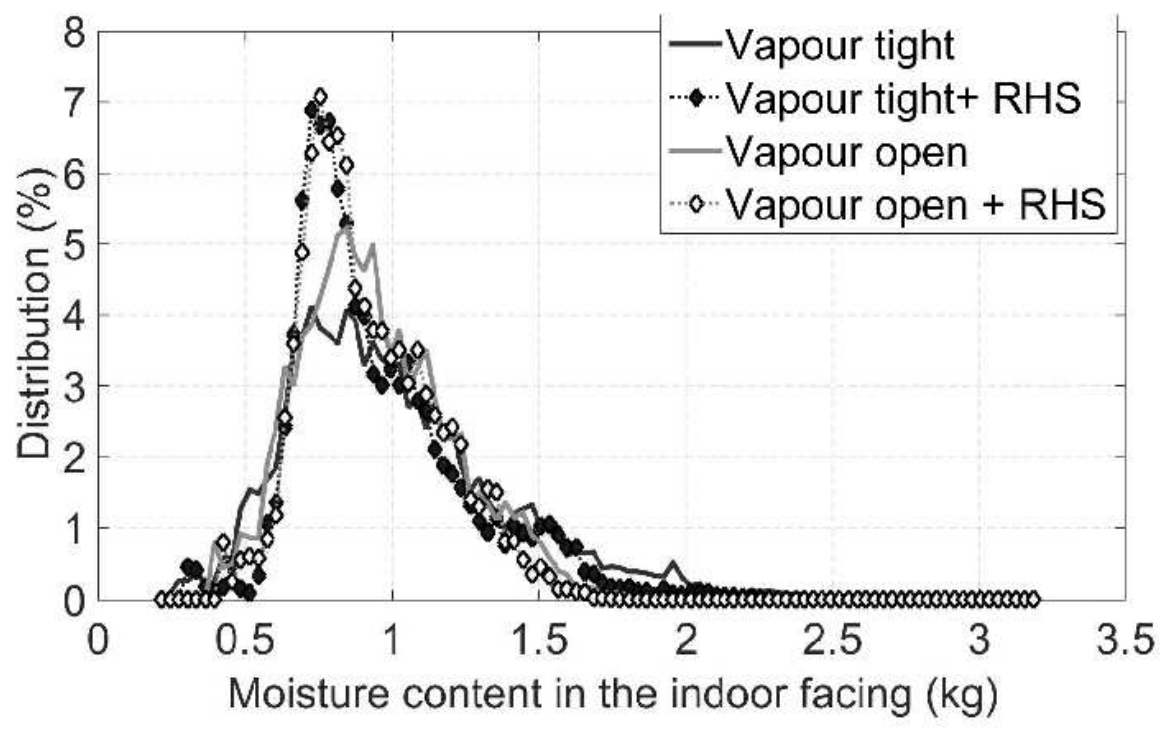

Figure 15: Distribution of the moisture content for the indoor siding

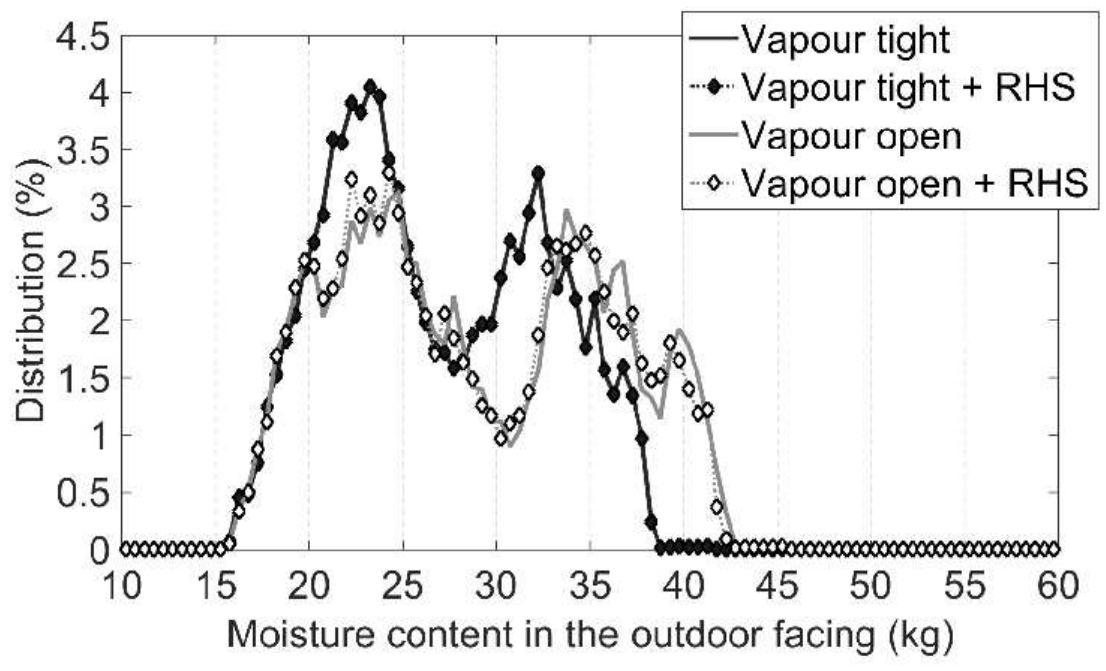

Figure 16: Distribution of the moisture content for the outdoor siding 


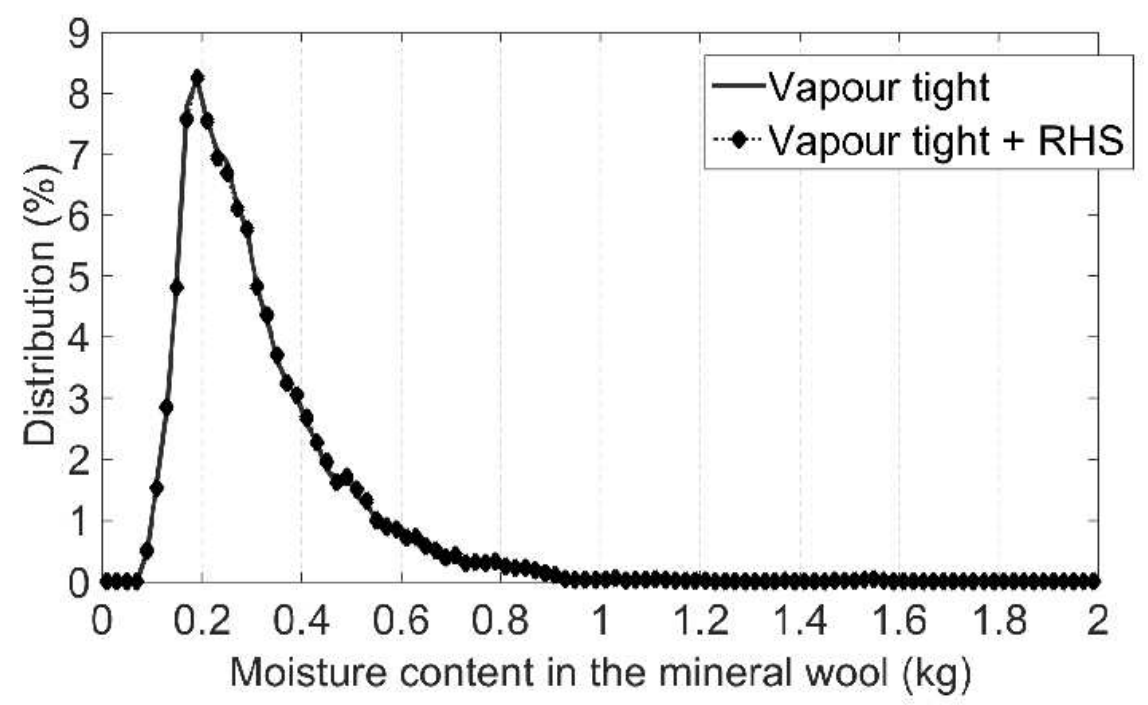

Figure 17: Distribution of the moisture content for the mineral wool with both types of ventilation

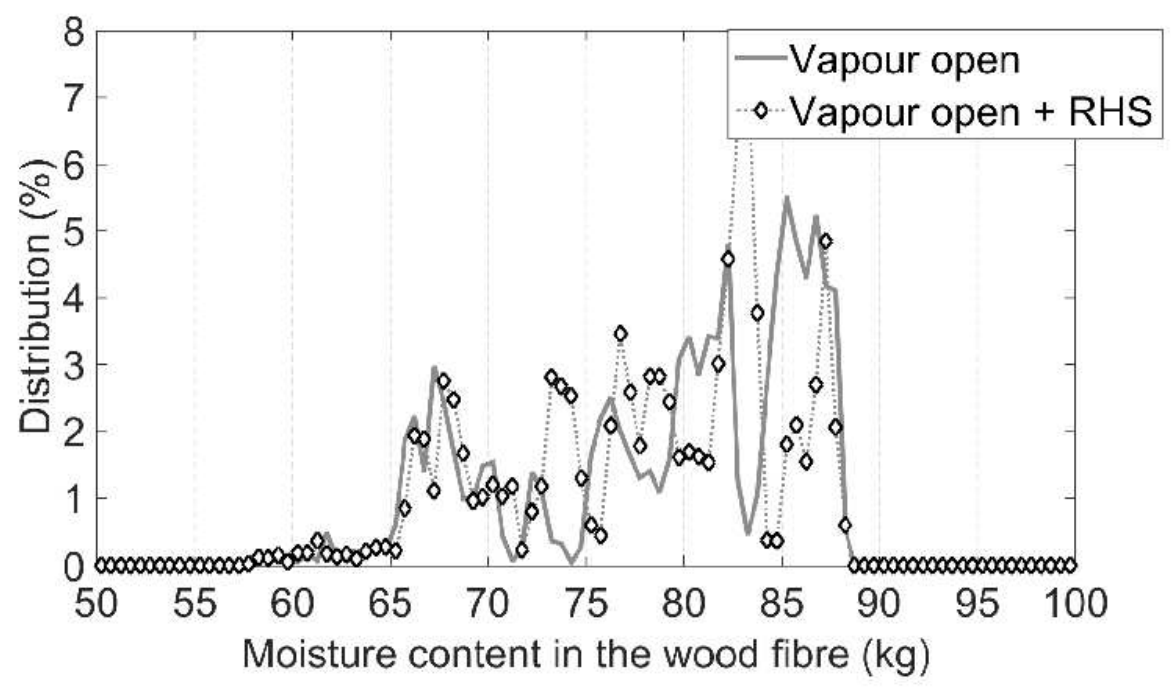

Figure 18 : Distribution of the moisture content for the wood fibre with both types of ventilation

First, it was observed that the moisture content could differ by one order of magnitude: it was rather low in the indoor siding $(0.2-3.0 \mathrm{~kg})$ compared to the outdoor siding $(15-47 \mathrm{~kg})$. For the insulation, lower values were observed with mineral wool $(0.1-1.6 \mathrm{~kg})$ than with wood fibre $(63-88 \mathrm{~kg})$. The moisture content in the indoor siding followed indoor humidity closely as a result of the high vapour permeability of gypsum boards. Consequently, the shape of the distribution for the indoor siding was similar to that of the indoor humidity. However, the 
average moisture content was decreased by $7 \%$ by replacing the vapour-tight assembly with the vapour-open assembly, which was equivalent to the use of the RHS ventilation (6\%). This means that this wall assembly had greater influence on the moisture content of the indoor siding than on indoor humidity.

Concerning the outdoor siding, two peak distributions can be observed (23 and $33 \mathrm{~kg}$ ) in Figure 16. This was due to seasonal variations: moisture tended to be stored within the outdoor siding during winter and released during summer. It was observed that the use of RHS ventilation had almost no impact. On the other hand, the moisture content increased when wood fibre was used instead of mineral wool. This was more visible for the second peak: the moisture content exceeded $35 \mathrm{~kg}$ during $27 \%$ of the year versus $12 \%$ with mineral wool. It can be concluded that the moisture sorption property of wood fibre had an impact on both sidings but it was greater on the outdoor siding. The use of RHS ventilation had no impact on the moisture distribution for mineral wool because of the vapour barrier. In contrast, the distribution in wood fibre was irregular and strongly influenced by the use of the RHS ventilation. Consequently, there was a combination of both RHS ventilation and the wood fibre hygroscopic properties, although it had a low impact on indoor humidity. Finally, the average value was nearly the same $(78 \mathrm{~kg}$ ) with or without RHS ventilation.

These results show that the moisture balance in the wall was very different for the four cases simulated. However, it was hard to assess which one was the best on the basis of the moisture content alone. Therefore, the analysis of the results had to be expanded, by considering the durability of the wall assembly for example.

\subsubsection{Durability estimation}

According to Isaksson et al. (2010), durability is the capacity of the structure to give a required performance during an intended service period under the influence of degradation 
mechanisms. In this case, mould growth is the most likely degradation mechanism. Pernilla Johansson et al. (2012) and Van den Bulcke et al. (2011) conducted measurements on material samples and then proposed a model able to predict mould growth. It should be noted that various behaviours were observed depending on the material, the mould type and the boundary conditions. This point was underlined by Isaksson et al. (2010), who studied the risk of mould growth over a 40-year period for actual climate conditions. The results varied greatly from one year to another. For practical reasons, however, many authors considered shorter periods (Salonvaara, Karagiozis, and Holm, 2001; Karagiozis and Salonvaara, 2001; Steeman, Janssens, and De Paepe 2009). At the building scale, several methods for estimating mould growth were reviewed by Vereecken and Roels (2012), who provided the main limits and a comparison. From a general point of view, it seemed difficult to assess which method was the best. Nonetheless, it was underlined that a single method could be used to give a qualitative comparison of the different cases. One of these methods was developed at the VTT (Technical Research Centre of Finland) by Hukka and Viitanen (1999) and improved by Ojanen et al. (2010). Its main advantage is that it can be applied to a wide range of materials and used for dynamic boundary conditions. It is based on the calculation of the mould index, which includes the effects of exposure time, temperature, relative humidity and dry periods. Moreover, it was demonstrated that the decline of mould under unfavourable conditions for its growth was not immediate, and this was taken into account in the model.

In the present paper, this approach was used to achieve preliminary calculations and did not show a high risk of mould growth for any of the four cases simulated. To be more precise, the computed mould index remained equal to zero most of the time. This means that favourable mould growth conditions were obtained only punctually. Therefore, the differences were not significant between the four simulated cases. Similar results have been obtained (Karagiozis and Salonvaara 2001) for a vapour permeable wall despite the use of very high value of initial 
relative humidity. Therefore, a second approach was used; the threshold value for mould growth $\left(R H_{C r i t}\right)$ was computed with (6) and compared with the numerical results for each node. The $R H_{\text {Min }}$ values used in (6) were presented by (Ojanen et al. 2010) and depended on the material. In some ways, this is a steady-state-based approach similar to the use of the Sedbauer's isopleths (Latif et al. 2015; Vereecken and Roels 2012).

$$
R H_{C r i t}= \begin{cases}\text { if } T \leq 20^{\circ} \mathrm{C} & 100-3.13 \cdot T+0.160 \cdot T^{2}-0.00267 \cdot T^{3} \\ \text { if } T>20^{\circ} \mathrm{C} & R H_{\text {Min }}\end{cases}
$$

Finally, the cumulative exceedance was calculated by adding up the times the threshold value was exceeded. A similar approach was used by Walker and Sherman (2007). The results are presented in Figure 19 and Figure 20 for the northern and the southern walls, respectively.

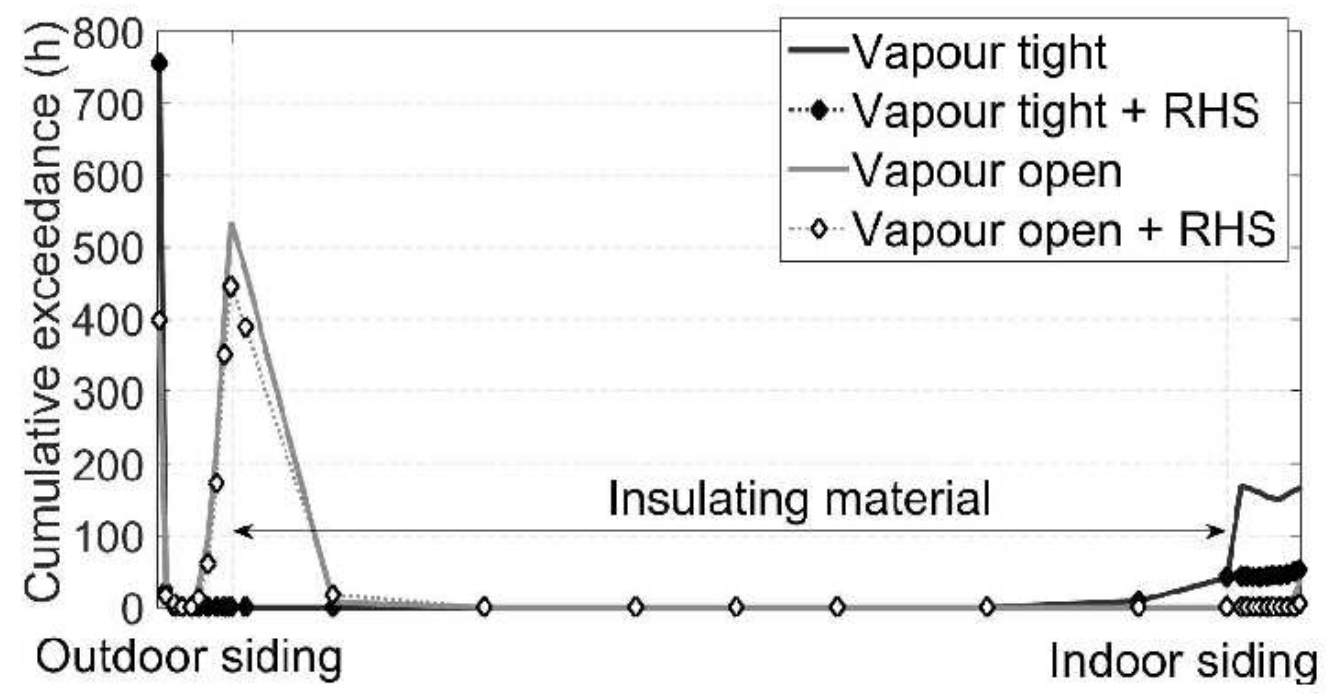

Figure 19: Cumulative exceedance of the critical relative humidity computed for each node in the northern wall for the four simulated cases. 


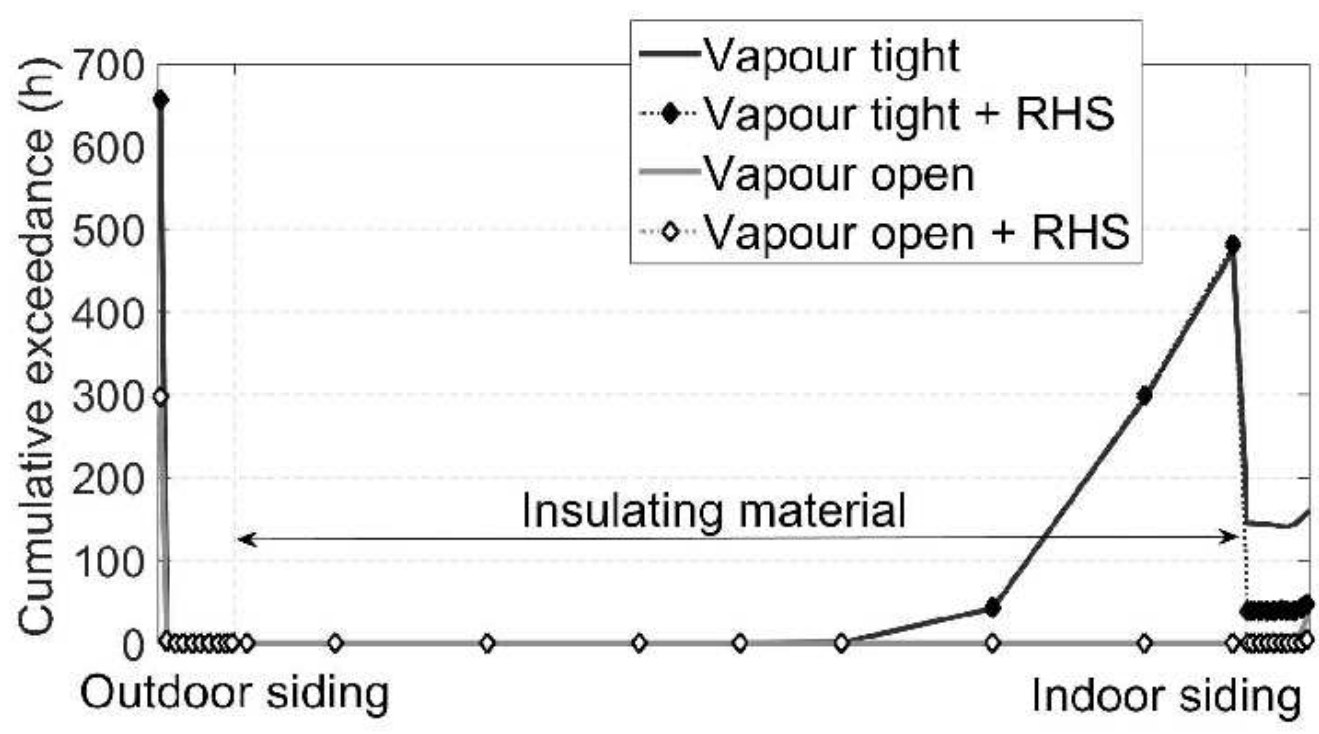

Figure 20: Cumulative exceedance of the critical relative humidity computed for each node in the southern wall for the four simulated cases.

The highest values (up to $750 \mathrm{~h}$ per year) were computed at the surface of the outdoor siding. However, it should be noted that the threshold was exceeded very often and for short periods of time $(<15 \mathrm{~h})$. In fact, this high value resulted from the thinness of the node $(1.5 \mathrm{~mm})$ and from the outdoor conditions, which were often very close to the $R H_{\text {Min }}$ value. For the other nodes of the outdoor siding, the threshold value for mould growth was almost never reached. For the insulating material, the results were more scattered and need to be discussed in greater detail.

At the interface between the outdoor siding and wood fibre, the threshold was exceeded $400 \mathrm{~h}$ per year in the northern wall only. In fact, the computed values also came close to the threshold in the southern wall. On the other hand, the threshold was not exceeded in the rest of the wood fibre. This difference resulted from the binary analysis and the threshold value. Nonetheless, the simulated temperatures at this location were slightly higher than with mineral wool because of the higher thermal conductivity of wood fibre. As the threshold value depends on the temperature, there was a higher risk of mould growth at this location. It is difficult to predict whether or not this risk is acceptable. It might be handled by increasing the 
thickness of the insulation layer but this is not straightforward: as the temperature drops, the $R H_{c r i t}$ value increases as does the relative humidity of the material.

Concerning mineral wool, the threshold was exceeded at the interface with the vapour barrier and at depths of up to $37 \mathrm{~mm}$ in the material. Moreover, this effect was greater in the southern wall than in the northern wall because of the sun-driven vapour transfer (Piot et al. 2011; Carmeliet and Derome 2012): under strong solar irradiance, the moisture contained in the outdoor siding migrated into the insulating material. Because of the vapour barrier and the very low sorption capacity of the mineral wool, high relative humidity was observed in this part of the envelope, favouring mould growth.

The threshold value was exceeded for as long as $169 \mathrm{~h}$ per year in the indoor siding, mostly when moisture production was the highest. It should be noted that the risk was noticeably decreased by the use of a vapour-open wall: exceedance dropped to $36 \mathrm{~h}$ per year at the interface with indoor air, and was almost zero in the rest of the material. The impact of RHS ventilation was lower but the cumulative exceedance was decreased by half. Finally, the best results were obtained using both wood fibre and RHS ventilation.

To summarise, the risk for mould growth was not high for any of the four cases simulated, yet some differences were observed between the two wall assemblies. One identified risk for mould growth was that the vapour flow coming from indoors and outdoors increased the relative humidity close to the vapour barrier. This risk was substantially reduced by using the vapour-open wall configuration. It was further reduced by using RHS ventilation, but could not be completely avoided. This is consistent with the conclusions of other studies (Carey J. Simonson, Salonvaara, and Ojanen, 2001; Karagiozis and Salonvaara, 2001). 


\subsection{Comparison at the monthly scale}

\subsubsection{Air change rate with RHS ventilation}

This section reports on RHS ventilation only. The instantaneous values of the air change rate were used to compute monthly averaged values and the results are presented in Figure 21 . The average air change rate varied significantly during the year. This underlines the relevancy of using RHS ventilation. For example, lower values were required when the outdoor vapour pressure was the lowest, i.e. for cold periods ( $<0.5$ ach from December to March). On the other hand, higher airflow rates were suitable when conditions were mild (> 0.7 ach in September, October and May). For the latter case, RHS ventilation was used near to its maximum air change rate: this shows that the ventilation scheme could be improved to fit local climate conditions. The results were similar for the two wall configurations simulated. This is consistent with previous results, since it was observed that a vapour-permeable wall configuration had little influence on indoor air distribution (see Figure 14).

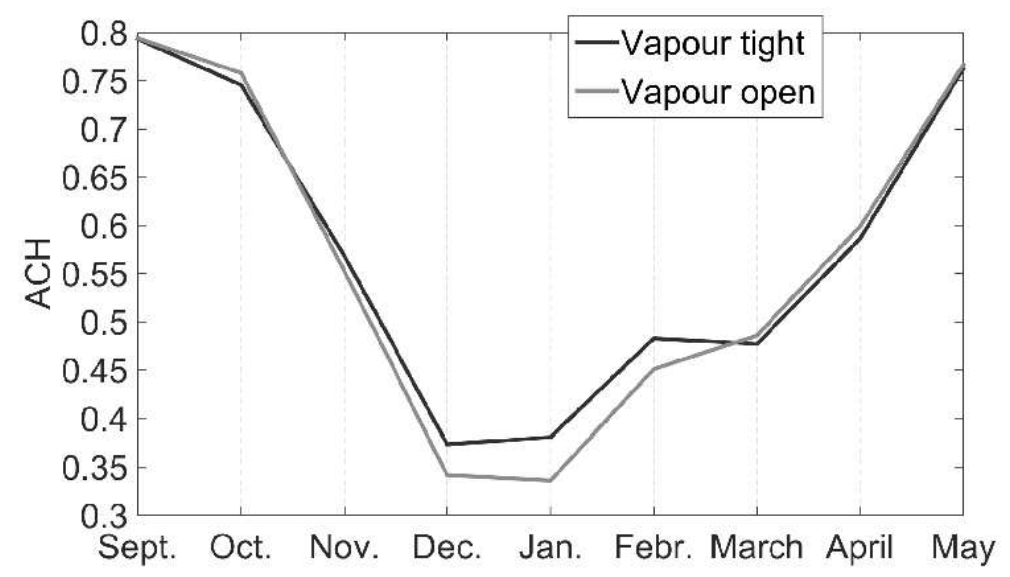

Figure 21: Monthly averaged air change rates for the two cases simulated with RHS ventilation.

\subsubsection{Vapour transfer with the vertical walls}

The vapour flow computed at the interface between indoor siding and indoor air was averaged 
monthly, by separating positive and negative vapour fluxes (adsorption and desorption phenomena, respectively). It was observed that both values were very close at the yearly scale $( \pm 0.3 \%)$ with a vapour barrier, while a noticeable difference was observed for the other cases: the vapour flux moving from indoors to the wall was $30 \%$ higher than the reverse flux. This means that a significant part of the absorbed vapour was not released indoors but moved through the wall assembly. For the sake of clarity, only the positive vapour fluxes are presented in Figure 22 in order to emphasise the ability of the vertical walls to smooth the impact of moisture production on indoor relative humidity.

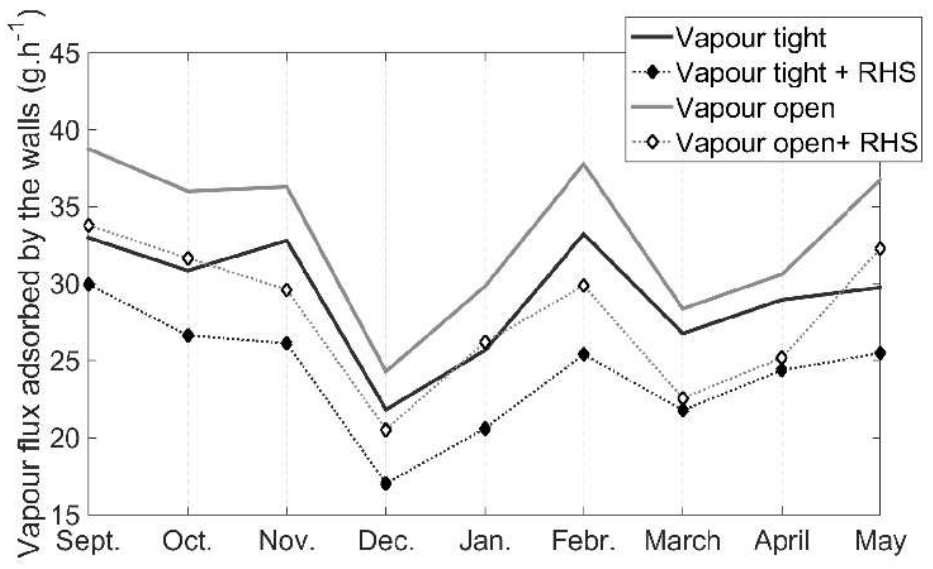

Figure 22: Monthly averaged buffering effect of indoor siding for the four cases simulated.

First, it can be seen that vapour transfer with the walls was not significantly increased by replacing a vapour-tight wall assembly with a vapour-open one; it was only $14 \%$ higher on average. Second, the average vapour transfer with the walls accounted for $20-45 \%$ of the average moisture production $\left(82 \mathrm{~g} \cdot \mathrm{h}^{-1}\right)$. This means that most of the moisture produced was removed by air renewal, and vapour transfer with the walls played a less significant role. As the simulated air change rate was representative of building practices and the occupancy scenario was defined to enhance moisture production, it can be concluded that the use of a vapour-open wall assembly leads to increased vapour transfer with the walls but that the impact on the moisture balance at the room scale is rather low. 
Finally, vapour transfer with the walls was decreased by $17 \%$ for both wall assemblies when using RHS ventilation. This can be easily explained given that RHS ventilation is intended to reduce the impact of moisture production on indoor air humidity. The vapour transfer still evolved over the year, decreasing by more than $25 \%$ from September to January (December was a particular case because it was assumed the inhabitant left the building from the $24^{\text {th }}$ to the end of the month). This variation can be explained by the impact of the ventilation on the moisture balance and by the outdoor conditions: the outdoor vapour pressure was the highest in September, which decreased the impact of the ventilation on the moisture balance. Therefore, vapour transfers with the walls were greater.

\subsubsection{Heating power}

The heating power used is representative of energy consumption; it was computed by averaging instantaneous power demand over 1 month, which was simulated to maintain the indoor air temperature at $20^{\circ} \mathrm{C}$. The results are presented in Figure 23 . Generally speaking, the energy consumption was higher (10-15\%) with wood fibre than with mineral wool because the thermal conductivity for wood fibre is $16 \%$ higher than for mineral wool (see Table 2). An interesting point is that the yearly energy consumption for heating was not modified by RHS ventilation $(\sim 1 \%)$. However, the energy demand for heating was not the same at the monthly scale. Higher air change rates were computed for mild periods, which resulted in higher thermal losses $(+25 \%$ in October; $+35 \%$ in May). For cold periods, on the other hand, the opposite was true ( $-15 \%$ in December and January). In some ways, the use of RHS ventilation smoothed the energy demand. 


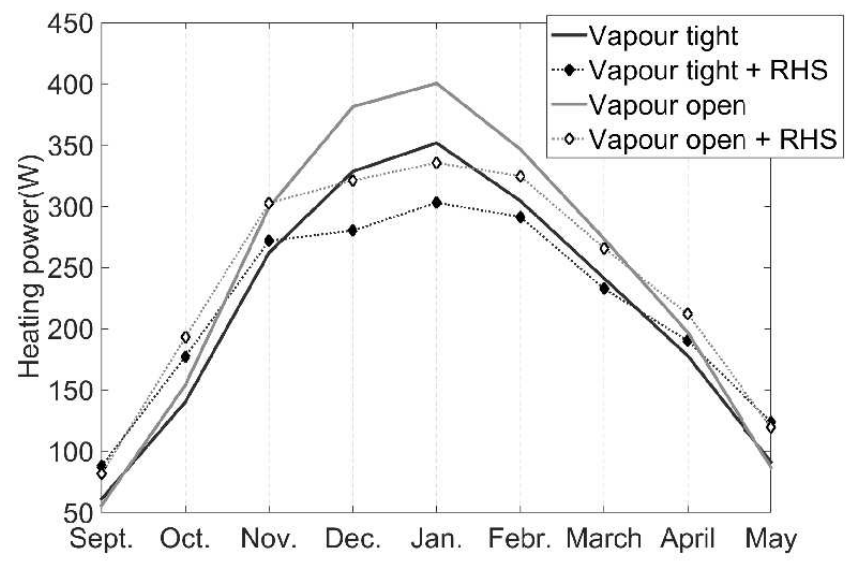

Figure 23: Monthly averaged heating power for the four cases simulated.

\subsection{General discussion}

\subsubsection{Comparison of the 4 simulated cases}

The results presented in the two previous sections are summarised in the overall analysis of Appendix 3 and Appendix 4. The use of RHS ventilation instead of the constant ventilation resulted in one significant improvement: indoor comfort was noticeably increased by targeting the desired range of humidity and by avoiding extreme humidity. At the same time, the average heating consumption was almost the same and the heating demand was smoothed. Consequently, there is no drawback to using an RHS system.

Concerning a hygroscopic and vapour-open wall configuration, the results were not straightforward. First, wood fibre was able to buffer larger amounts of vapour than a nonhygroscopic insulating material such as mineral wool. For the simulated cases, however, it had a greater impact on the moisture content of the outdoor siding than on the indoor conditions. As a result, using wood fibre improved indoor comfort only slightly. Second, this wall assembly was found to have better durability (less risk of mould growth) than the assembly made of mineral wool with a vapour barrier. However, the risk for mould growth 
was mostly related to the use of the vapour barrier. Therefore, it is very difficult to clearly explain whether the improvement was related to the use of wood fibre or to the removal of the vapour barrier. Finally, energy consumption was increased by $10-15 \%$. However, this can be easily explained by the higher thermal conductivity of wood fibre and handled by increasing its thickness. Overall, it seems relevant to use a vapour-open wall assembly in wooden-frame houses.

For the last case, where a vapour-open wall assembly and RHS ventilation were used, both effects were combined. Nevertheless, it was confirmed that indoor moisture production was mostly balanced by air renewal. Consequently, the vapour transfer with the walls did not have much effect: in some ways, the advantageous sorption capacity of wood fibre was under-used, as far as indoor climate was concerned. Moreover, the simulated building and input parameters were selected so that the buffering effect was favoured (high moisture production, low indoor volume, no covering on the indoor sidings, stay-at-home behaviour, minimum air change rate, etc.). Hygroscopic insulating material has no apparent utility in the management of indoor humidity in dwellings. Using RHS ventilation is far more relevant. On the other hand, highly hygroscopic insulation such as wood fibre appeared to be an advantageous alternative to the combination of non-hygroscopic materials, such as mineral wool, and a vapour barrier because it improved the durability of the construction.

\subsubsection{Influence of the moisture production schedule}

As previously mentioned, the need for modelling a detailed moisture production schedule is not clearly demonstrated in the literature. In order address this issue, the four cases were simulated a second time by using a constant moisture production schedule. The moisture production rate was chosen to be equal to the average value used with the variable schedule $\left(82\right.$ g.h $\left.\mathrm{h}^{-1}\right)$. All the other parameters remained identical so that the influence of the moisture 
production schedule could be analysed. The results are shaded in grey in Appendix 3 and in Appendix 4.

The most significant difference was observed on the average vapour flux exchanged between indoor air and the walls: it was underestimated by $50 \%$ to $80 \%$ when the variable moisture production schedule was replaced by the constant schedule. It should be underlined that this conclusion holds for all the four simulated cases but higher differences were observed with a vapour-tight wall assembly. This can be easily explained as the use of a constant schedule resulted in low indoor relative humidity variation. Consequently, the vapour pressure difference with the wall surfaces was small, as was the mass transfer. Therefore, the moisture balance at room scale was managed in a different way for the two schedules.

Another major difference was the distribution of indoor relative humidity. The estimation of the comfort range differed significantly depending on the type of schedule. Using a constant moisture production schedule resulted in an increase by $10 \%$ to $20 \%$ in the prediction of the comfort range, which is sizeable. On the other hand, the prediction of the discomfort range was not significantly modified (1 to $3 \%$ ). The greatest differences were observed when the RHS ventilation was used, for both wall assemblies. Besides, the average air flow rate for the RHS ventilation was overestimated by $7 \%$ when using the constant schedule. This is consistent with the solution of using both the RHS ventilation and the buffering effect: they are interesting to manage strong humidity variations. This can be illustrated by looking at the standard deviation of the airflow rate. It is higher for the RHS ventilation with a variable schedule (+/- 30\%) than with a constant schedule $(+/-20 \%)$. In the case of a constant moisture production schedule, indoor humidity variations were much smaller and could be simply handled by increasing the ventilation rate.

Finally, an increase in the ventilation rate resulted in an increase in heat losses, so the energy 
consumption for heating was slightly overestimated by the constant schedule $(+4 \%$ to $+6 \%)$. This difference is rather low but it should be underlined that the same magnitude was obtained by comparing the energy consumption of the two wall assemblies (all other parameters being the same). Therefore, it seems worthwhile to discuss the moisture production schedule as precisely as the other input parameters.

On the other hand, no significant difference was observed in the moisture content within the vertical walls. This resulted from the yearly analysis, as moisture accumulation within the materials is a long-term process, while the difference between the two schedules is significant only for short-term processes. Differences were observed on the calculated exceedance of a safe level from the mould growth point of view. As already mentioned in section 4.1.3, no significant risk was computed with the variable schedule, yet the safe level could be exceeded for more than 700 hours a year. The binary analysis of the results tends to highlight the positions where the relative humidity is close to the threshold level. In consequence, a small difference in the input parameter could result in a strong variation of the results but it may not be significant in terms of durability. This leads to the conclusion that the durability should not be significantly influenced by the moisture production schedule.

To sum up, this numerical work illustrated the intuitive idea that the moisture production schedule mainly influenced short-term processes. In other words, its most marked impact was on the moisture balance of indoor air. The strongest influence was observed when the RHS ventilation was used.

\section{Conclusion}

A validated numerical model was used to simulate coupled heat and vapour transfer in the envelope and in the indoor air of a wooden-frame dwelling. Four cases were tested in order to highlight the impact of the use of hygroscopic insulating material and of RHS ventilation on 
moisture management at room scale. The input parameters represented substantial indoor moisture production to emphasise the differences between the four cases. Moisture production due to occupancy was modelled using a stochastic approach. The entire-year behaviour was simulated for the outdoor conditions existing in Grenoble, France.

The results showed that RHS ventilation efficiently improved indoor comfort and did not increase energy consumption. The durability of a typical wall assembly composed of mineral wool and a vapour barrier was improved by using a vapour-open wall assembly instead of a vapour-tight assembly. Both solutions improved the overall performance of the building. However, it was observed that indoor moisture production was mostly balanced by air renewal, obviating the need for hygroscopic insulating material in the management of indoor humidity in dwellings, although this is an acceptable alternative to a vapour-tight wall assembly. The influence of the modelling of moisture production was discussed by comparing the results with those using a constant moisture production schedule. Significant differences were observed for short-term phenomena (mainly when the RHS ventilation was used) while the moisture production had almost no impact on long-term phenomena (namely the estimation of durability).

\section{References}

Abadie, Marc Olivier, and Kátia Cordeiro Mendonça. 2009. "Moisture Performance of Building Materials: From Material Characterization to Building Simulation Using the Moisture Buffer Value Concept." Building and Environment 44 (2): 388-401. doi:10.1016/j.buildenv.2008.03.015.

Aerts, F., D. Minnen, I. Glorieux, I. Wouters, and F. Descamps. 2013. "Discrete Occupancy Profiles from Time-Use Data for User Behavior Modeling in Homes." In , 2421-27. Chambéry, France.

$\begin{array}{lllll}\text { Arrêté } & \mathrm{Du} & 24 & \text { Mars } & 1982 .\end{array}$ http://www.legifrance.gouv.fr/affichTexte.do?cidTexte=JORFTEXT000000862344.

Carmeliet, Jan, and Dominique Derome. 2012. "Temperature Driven Inward Vapor Diffusion under Constant and Cyclic Loading in Small-Scale Wall Assemblies: Part 1 Experimental Investigation." Building and Environment 48 (February): 48-56. doi:10.1016/j.buildenv.2011.08.015.

Carmeliet, Jan, M. De Wit, and Hans Janssen. 2005. "Hysteresis and Moisture Buffering of Wood." In Symposium of Building Physics in the Nordic Countries, 55-62. http://web.byv.kth.se/bphys/reykjavik/pdf/art_032.pdf. 
Casey, S.P., M.R. Hall, S.C.E. Tsang, and M.A. Khan. 2013. "Energetic and Hygrothermal Analysis of a Nano-Structured Material for Rapid-Response Humidity Buffering in Closed Environments." Building and Environment 60 (February): 24-36. doi:10.1016/j.buildenv.2012.11.007.

Desta, Tadiwos Zerihun, Jelle Langmans, and Staf Roels. 2011. "Experimental Data Set for Validation of Heat, Air and Moisture Transport Models of Building Envelopes." Building and Environment 46 (5): 1038-46. doi:10.1016/j.buildenv.2010.11.002.

Diasty, R. El, P. Fazio, and I. Budaiwi. 1992. "Modelling of Indoor Air Humidity: The Dynamic Behaviour within an Enclosure." Energy and Buildings 19: 61-73.

Djebbar, Reda, David van Reenen, and Mavinkal K. Kumaran. 2001. "Environmental Boundary Conditions for Long-Term Hygrothermal Calculations." Proceedings for Performance of Exterior Envelopes of Whole Buildings VIII: Integration of Building Envelopes, 2-7.

Emmerich, S. J., Andrew Persily, and Steven Nabinger. 2002. "Modeling Moisture in Residential Buildings with a Multizone IAQ Program." Gaithersbur, MD: National Institute of Standards and Technology. http://fire.nist.gov/bfrlpubs/build03/PDF/b03007.pdf.

European Standard EN 15251:2007. Indoor Environmental Input Parameters for Design and Assessment of Energy Performance of Buildings Addressing Indoor Air Quality, Thermal Environment, Lighting and Acoustics. CEN, European Committee for Standardization.

Ge, Hua, Xiangjin Yang, Paul Fazio, and Jiwu Rao. 2014. "Influence of Moisture Load Profiles on Moisture Buffering Potential and Moisture Residuals of Three Groups of Hygroscopic Materials." Building and Environment 81 (November): 162-71. doi:10.1016/j.buildenv.2014.06.021.

Ghali, K., O. Katanani, and M. Al-Hindi. 2011. "Modeling the Effect of Hygroscopic Curtains on Relative Humidity for Spaces Air Conditioned by DX Split Air Conditioning System." Energy and Buildings 43 (9): 2093-2100. doi:10.1016/j.enbuild.2011.04.017.

Hameury, Stéphane. 2005. "Moisture Buffering Capacity of Heavy Timber Structures Directly Exposed to an Indoor Climate: A Numerical Study." Building and Environment 40 (10): 1400-1412. doi:10.1016/j.buildenv.2004.10.017.

Hens, H. 2007. Building Physics - Heat, Air and Moisture. Ernst \& Sohn, Berlin, Germany.

Hukka, A., and H. A. Viitanen. 1999. "A Mathematical Model of Mould Growth on Wooden Material." Wood Science and Technology 33 (6): 475-85.

IEA Annex XIV. 1991. Condensation and Energy - Sourcebook.

Isaksson, Tord, Sven Thelandersson, Annika Ekstrand-Tobin, and Pernilla Johansson. 2010. "Critical Conditions for Onset of Mould Growth under Varying Climate Conditions." Building and Environment 45 (7): 1712-21. doi:10.1016/j.buildenv.2010.01.023.

Isetti, C., L. Laurenti, and A. Ponticello. 1988. "Predicting Vapour Content of the Indoor Air and Latent Loads for Air-Conditioned Environments: Effect of Moisture Storage Capacity of the Walls." Energy and Buildings 12: 141-48.

Janssen, Hans, and Staf Roels. 2009. "Qualitative and Quantitative Assessment of Interior Moisture Buffering by Enclosures." Energy and Buildings 41 (4): 382-94. doi:10.1016/j.enbuild.2008.11.007.

Janssens, Arnold, and Michel De Paepe. 2005. "Effect of Moisture Inertia Models on the Predicted Indoor Humidity in a Room." In Proceedings of the 26th AIVC Conference, Brussels, 287-94. http://www.kuleuven.ac.be/bwt/projects/annex41/protected/data/UG\%20Oct\%202005\%20BGi nf\%20A41-T1-B-05-2.pdf.

Johansson, Pär, Simon Pallin, and Mohammad Shahriari. 2010. "Risk Assessment Model Applied on Building Physics: Statistical Data Acquisition and Stochastic Modeling of Indoor Moisture Supply in Swedish Multi-Family Dwellings." In IEA Annex 55 RAP-RETRO. Copenhagen.

Johansson, Pernilla, Annika Ekstrand-Tobin, Thomas Svensson, and Gunilla Bok. 2012. "Laboratory Study to Determine the Critical Moisture Level for Mould Growth on Building Materials." International Biodeterioration \& Biodegradation 73 (September): 23-32. doi:10.1016/j.ibiod.2012.05.014. 
Kalagasidis, Angela Sasic, Peter Weitzmann, Toke Rammer Nielsen, Ruut Peuhkuri, Carl-Eric Hagentoft, and Carsten Rode. 2007. "The International Building Physics Toolbox in Simulink." Energy and Buildings 39 (6): 665-74. doi:10.1016/j.enbuild.2006.10.007.

Kalamees, T. 2006. "Indoor Humidity Loads and Moisture Production in Lightweight Timber-Frame Detached Houses." Journal of Building Physics 29 (3): 219-46. doi:10.1177/1744259106060439.

Karagiozis, Achilles, and Mikael Salonvaara. 2001. "Hygrothermal System-Performance of a Whole Building." Building and Environment 36 (6): 779-87.

Kwiatkowski, Jerzy, Monika Woloszyn, and Jean-Jacques Roux. 2009. "Modelling of Hysteresis Influence on Mass Transfer in Building Materials." Building and Environment 44 (3): 633-42. doi:10.1016/j.buildenv.2008.05.006.

Labat, Matthieu, Monika Woloszyn, Géraldine Garnier, Amandine Piot, and Jean-Jacques Roux. 2013. "Simulation of Coupled Heat, Air and Moisture Transfers in an Experimental House Exposed to Natural Climate." In Proceedings of BS2013: 13th Conference of International Building Performance Simulation Association, August 26-28. Chambéry, France,. http://www.ibpsa.org/proceedings/BS2013/p_1121.pdf.

Labat, Matthieu, Monika Woloszyn, Géraldine Garnier, and Jean Jacques Roux. 2013. "Assessment of the Air Change Rate of Airtight Buildings under Natural Conditions Using the Tracer Gas Technique. Comparison with Numerical Modelling." Building and Environment 60 (February): 37-44. doi:10.1016/j.buildenv.2012.10.010.

Labat, Matthieu, Monika Woloszyn, Géraldine Garnier, and Jean Jacques Roux. 2015. "Dynamic Coupling between Vapour and Heat Transfer in Wall Assemblies: Analysis of Measurements Achieved under Real Climate." Building and Environment 87 (May): 129-41. doi:10.1016/j.buildenv.2015.01.022.

Labat, Matthieu, Monika Woloszyn, Geraldine Garnier, Gilles Rusaouen, and Jean Jacques Roux. 2012. "Impact of Direct Solar Irradiance on Heat Transfer behind an Open-Jointed Ventilated Cladding: Experimental and Numerical Investigations." Solar Energy 86 (9): 2549-60. doi:10.1016/j.solener.2012.05.030.

Latif, Eshrar, Mihaela Anca Ciupala, Simon Tucker, Devapriya Chitral Wijeyesekera, and Darryl John Newport. 2015. "Hygrothermal Performance of Wood-Hemp Insulation in Timber Frame Wall Panels with and without a Vapour Barrier." Building and Environment 92 (October): 122-34. doi:10.1016/j.buildenv.2015.04.025.

Laverge, J., X. Pattyn, and A. Janssens. 2013. "Performance Assessment of Residential Mechanical Exhaust Ventilation Systems Dimensioned in Accordance with Belgian, British, Dutch, French and ASHRAE Standards." Building and Environment 59 (January): 177-86. doi:10.1016/j.buildenv.2012.08.018.

Li, Yang, Paul Fazio, and Jiwu Rao. 2012. "An Investigation of Moisture Buffering Performance of Wood Paneling at Room Level and Its Buffering Effect on a Test Room." Building and Environment 47 (January): 205-16. doi:10.1016/j.buildenv.2011.07.021.

$\mathrm{Li}$, Yuguo, and Angelo Delsante. 2001. "Natural Ventilation Induced by Combined Wind and Thermal Forces." Building and Environment, no. 36: 59-71.

Lu, Xiaoshu. 2003. "Estimation of Indoor Moisture Generation Rate from Measurement in Buildings." Building and Environment 38 (5): 665-75. doi:10.1016/S0360-1323(02)00237-8.

Mualem, Yechezkel. 1974. "A Conceptual Model of Hysteresis." Water Resources Research 10 (3): 514-20.

Ojanen, Tuomo, Hannu Viitanen, Ruut Peuhkuri, Kimmo Lähdesmäki, Juha Vinha, and Kati Salminen. 2010. "Mold Growth Modeling of Building Structures Using Sensitivity Classes of Materials."

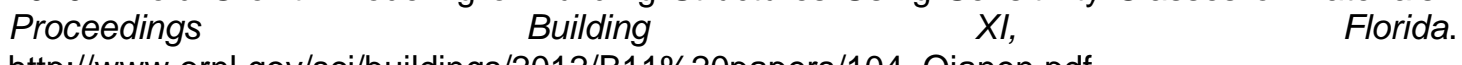
http://www.ornl.gov/sci/buildings/2012/B11\%20papers/104_Ojanen.pdf.

Orosa, José A., and A. Baaliña. 2009. "Improving PAQ and Comfort Conditions in Spanish Office Buildings with Passive Climate Control." Building and Environment 44 (3): 502-8. doi:10.1016/j.buildenv.2008.04.013. 
Osanyintola, Olalekan F., and Carey J. Simonson. 2006. "Moisture Buffering Capacity of Hygroscopic Building Materials: Experimental Facilities and Energy Impact." Energy and Buildings 38 (10): 1270-82.

Page, J., D. Robinson, N. Morel, and J.-L. Scartezzini. 2008. "A Generalised Stochastic Model for the Simulation of Occupant Presence." Energy and Buildings 40 (2): 83-98. doi:10.1016/j.enbuild.2007.01.018.

Parys, Wout, Dirk Saelens, and H. Hens. 2011. "Coupling of Dynamic Building Simulation with Stochastic Modelling of Occupant Behaviour in Offices-a Review-Based Integrated Methodology." Journal of Building Performance Simulation 4: 339-58. doi:10.1080/19401493.2010.524711.

Piot, Amandine, Monika Woloszyn, Jean Brau, and Charlotte Abele. 2011. "Experimental Wooden Frame House for the Validation of Whole Building Heat and Moisture Transfer Numerical Models." Energy and Buildings 43 (6): 1322-28. doi:10.1016/j.enbuild.2011.01.008.

Plathner, Philipp, and Monika Woloszyn. 2002. "Interzonal Air and Moisture Transport in a Test House: Experiment and Modelling." Building and Environment 37: 189-99.

Qin, Menghao, George Walton, Rafik Belarbi, and Francis Allard. 2011. "Simulation of Whole Building Coupled Hygrothermal-Airflow Transfer in Different Climates." Energy Conversion and Management 52 (2): 1470-78. doi:10.1016/j.enconman.2010.10.010.

Ramos, N.M.M., J.M.P.Q. Delgado, and V.P. de Freitas. 2010. "Influence of Finishing Coatings on Hygroscopic Moisture Buffering in Building Elements." Construction and Building Materials 24 (12): 2590-97. doi:10.1016/j.conbuildmat.2010.05.017.

Rode, Carsten, Ruut Hannele Peuhkuri, Lone Hedegaard Mortensen, Kurt Kielsgaard Hansen, Berit Time, Arild Gustavsen, Tuomo Ojanen, et al. 2005. Moisture Buffering of Building Materials. Technical University of Denmark, Department of Civil Engineering. http://orbit.dtu.dk/fedora/objects/orbit:75984/datastreams/file_2415500/content.

Roels, S., and H. Janssen. 2006. "A Comparison of the Nordtest and Japanese Test Methods for the Moisture Buffering Performance of Building Materials." Journal of Building Physics 30 (2): 137-61. doi:10.1177/1744259106068101.

Salonvaara, M, A Karagiozis, and A Holm. 2001. "Stochastic Building Envelope modeling-The Influence of Material Properties." In . Thermal Performance of Exterior Envelopes of Whole Buildings VIII.

Simonson, Carey J., M. Salonvaara, and Tuomo Ojanen. 2001. "Moisture Content of Indoor Air and Structures in Buildings with Vapor Permeable Envelopes." Performance of Exterior Envelopes of Whole Buildings VIII. http://www.ornl.gov/sci/buildings/2012/2001/141.pdf.

Simonson, C. J., M. Salonvaara, and T. Ojanen. 2002. "The Effect of Structures on Indoor Humiditypossibility to Improve Comfort and Perceived Air Quality." Indoor Air 12 (4): 243-51.

Steeman, Marijke, Arnold Janssens, and Michel De Paepe. 2009. "Performance Evaluation of Indirect Evaporative Cooling Using Whole-Building Hygrothermal Simulations." Applied Thermal Engineering 29 (14-15): 2870-75. doi:10.1016/j.applthermaleng.2009.02.004.

TenWolde, Anton, and I. Walker. 2001. "Interior Moisture Design Loads for Residences." Proc. Thermal Performance of Exterior Envelopes of Buildings VIII. ASHRAE, Atlanta, GA. http://www.ornl.gov/sci/buildings/2012/2001\%20B8\%20papers/033_Password_Removed.pdf.

Van den Bulcke, Jan, Imke De Windt, Nele Defoirdt, Jordi De Smet, and Joris Van Acker. 2011. "Moisture Dynamics and Fungal Susceptibility of Plywood." International Biodeterioration \& Biodegradation 65 (5): 708-16. doi:10.1016/j.ibiod.2010.12.015.

Vereecken, E., and S. Roels. 2012. "Review of Mould Prediction Models and Their Influence on Mould Risk Evaluation." Building and Environment 51 (May): 296-310. doi:10.1016/j.buildenv.2011.11.003.

Vereecken, E., S. Roels, and H. Janssen. 2011. "In Situ Determination of the Moisture Buffer Potential of Room Enclosures." Journal of Building Physics 34 (3): 223-46. doi:10.1177/1744259109358268. 
Walker, lain S., and Max H. Sherman. 2007. "Humidity Implications for Meeting Residential Ventilation Requirements." Berkeley, CA: Lawrence Berkeley National Laboratory, LBNL-62182. http://www.ornl.org/sci/buildings/2010/Session\%20PDFs/197_New.pdf.

Wolkoff, Peder, and Søren K. Kjærgaard. 2007. "The Dichotomy of Relative Humidity on Indoor Air Quality." Environment International 33 (6): 850-57. doi:10.1016/j.envint.2007.04.004.

Woloszyn, Monika, Targo Kalamees, Marc Olivier Abadie, Marijke Steeman, and Angela Sasic Kalagasidis. 2009. "The Effect of Combining a Relative-Humidity-Sensitive Ventilation System with the Moisture-Buffering Capacity of Materials on Indoor Climate and Energy Efficiency of Buildings." Building and Environment 44 (3): 515-24. doi:10.1016/j.buildenv.2008.04.017.

Woloszyn, Monika, and Carsten Rode. 2008. "Tools for Performance Simulation of Heat, Air and Moisture Conditions of Whole Buildings." Building Simulation 1 (1): 5-24.

Yang, Xiangjin, Paul Fazio, Hua Ge, and Jiwu Rao. 2012. "Evaluation of Moisture Buffering Capacity of Interior Surface Materials and Furniture in a Full-Scale Experimental Investigation." Building and Environment 47 (January): 188-96. doi:10.1016/j.buildenv.2011.07.025.

Yoshino, H., T. Mitamura, and K. Hasegawa. 2009. "Moisture Buffering and Effect of Ventilation Rate and Volume Rate of Hygrothermal Materials in a Single Room under Steady State Exterior Conditions." Building and Environment 44 (7): 1418-25. doi:10.1016/j.buildenv.2008.09.007.

Zhang, Huibo, Hiroshi Yoshino, and Kenichi Hasegawa. 2012. "Assessing the Moisture Buffering Performance of Hygroscopic Material by Using Experimental Method." Building and Environment 48 (February): 27-34. doi:10.1016/j.buildenv.2011.08.012. 


\section{Appendices - Tables}

Appendix 1: Values used to determine the moisture production for each activity.

\begin{tabular}{|c|c|c|c|c|}
\hline Activity & Frequency & Start & Duration (min) & Moisture released (g) \\
\hline Shower & 0.85 times a day & See Figure 12 & $10^{(1)}$ & $250 \pm 50$ \\
\hline Cooking a meal & $\begin{array}{l}\text { Depends on whether or not } \\
\text { the occupant is at home }\end{array}$ & See Figure 12 & $\begin{array}{l}\text { Breakfast }=15 \pm 2^{(2)} \\
\text { Lunch }=30 \pm 2^{(2)} \\
\text { Dinner }=40 \pm 10^{(2)}\end{array}$ & $\begin{array}{l}\text { Breakfast }=109 \pm 20 \\
\text { Lunch }=288 \pm 68 \\
\text { Dinner }=518 \pm 152 \\
\text { Sum of the values from last } \\
\text { dishwashing: }\end{array}$ \\
\hline Dishwashing & Every day ${ }^{(2)}$ & See Figure 12 & $29 \pm 3$ & $\begin{array}{l}\text { Breakfast }=25 \pm 3 \\
\text { Lunch }=20 \pm 3 \\
\text { Dinner }=240 \pm 9\end{array}$ \\
\hline Clothes drying & $\begin{array}{l}\text { Once a week: } 24 \%{ }^{(4)} \\
\text { Twice a week: } 62 \%{ }^{(4)} \\
\text { Three times a week: } 14 \%^{(4)}\end{array}$ & $\begin{array}{l}\text { See Figure } 12{ }^{(3)} \\
\text { During the week: } 40 \% \\
\text { During the weekend: } 60 \%\end{array}$ & $11 \pm 2 \mathrm{~h}$ & $\begin{array}{l}1850 \pm 670 \\
20 \% \text { of the total amount is } \\
\text { released during the first hour, then } \\
\text { the emission rate is homogeneous }\end{array}$ \\
\hline Breathing & \multicolumn{3}{|c|}{$\begin{array}{l}\text { Busy: when doing some other activity (shower, meal, etc.); } \\
\text { Sleep: before the first activity or after the last activity (never between } 10.00 \text { and 21.00); } \\
\text { Rest: others. }\end{array}$} & $\begin{array}{l}\text { Busy }=70 \pm 5\left(\mathrm{~g} \cdot \mathrm{h}^{-1}\right) \\
\text { Sleep }=30 \pm 2\left(\mathrm{~g} \cdot \mathrm{h}^{-1}\right) \\
\text { Rest }=50 \pm 5\left(\mathrm{~g} \cdot \mathrm{h}^{-1}\right)\end{array}$ \\
\hline
\end{tabular}

(1) This activity is too brief considering the simulation time step, so its standard deviation cannot be taken into account.

(2) Assumptions: no value available.

(3) Values used for the "floor mopping" activity in (Pär Johansson, Pallin, and Shahriari 2010).

(4) These values are different from the values used in (Pär Johansson, Pallin, and Shahriari 2010). 
Appendix 2: General conditions reviewed for both numerical and experimental studies

\begin{tabular}{|c|c|c|c|c|c|c|c|c|c|c|}
\hline \multirow[b]{2}{*}{ Main author } & \multirow[b]{2}{*}{ Study ${ }^{(1)}$} & \multirow[b]{2}{*}{ Duration } & \multirow[b]{2}{*}{$\begin{array}{l}S \\
\left(m^{2}\right)\end{array}$} & \multirow[b]{2}{*}{$\begin{array}{l}\mathrm{V} \\
\left(\mathrm{m}^{3}\right)\end{array}$} & \multirow[b]{2}{*}{ Climate } & \multicolumn{3}{|c|}{ Moisture production } & \multicolumn{2}{|c|}{ Air change rate } \\
\hline & & & & & & Schedule & $\begin{array}{l}\text { Range. } \\
\left(\mathrm{g} \cdot \mathrm{h}^{-1}\right)\end{array}$ & $\begin{array}{l}\text { Average }{ }^{(2)} \\
\left(\mathrm{g} \cdot \mathrm{h}^{-1} \cdot \mathrm{m}^{-3}\right)\end{array}$ & Schedule & $\begin{array}{l}\text { Range } \\
\text { (ach) }\end{array}$ \\
\hline Simonson 01 & Exp. & 15 days & - & 29 & $\begin{array}{l}\text { Finland } \\
\text { (May) }\end{array}$ & Cycle & $0 ; 87$ & 1.00 & Constant & {$[0.06 ; 0.55]$} \\
\hline Simonson 02 & Num. & 5 days & 12 & 32 & $\begin{array}{l}\text { Belgium } \\
\text { (summer) }\end{array}$ & Cycle & $0 ; 60$ & 0.69 & Constant & 0.5 \\
\hline Yoshino 03 & Exp. & 2 days & - & 4,6 & $\begin{array}{l}\text { Controlled } \\
\text { conditions }\end{array}$ & Step & $0 ; 20$ & 1.09 & Constant & {$[0.62 ; 0.78]$} \\
\hline Lu 03 & Exp. & 4 days & 110 & 271 & $\begin{array}{l}\text { Finland } \\
\text { (winter) }\end{array}$ & Variable & {$[0 ; 700]$} & 0.75 & Variable & 0.4 \\
\hline Karagiozis 01 & Num. & 3 years & 300 & - & $\begin{array}{l}\text { USA } \\
\text { (Florida) }\end{array}$ & Cycle & {$[0 ; 1000]$} & 0.09 & Constant & 0.3 \\
\hline Hameury 05 & Num. & 3 days & 14 & 34 & $\begin{array}{l}\text { Sweden } \\
\text { (summer, winter) }\end{array}$ & Cycle & $\begin{array}{l}0 ; 60 \\
0 ; 120\end{array}$ & $0.59 ; 1.18$ & Constant & {$[0.05 ; 1]$} \\
\hline Salonvaara 01 & Num. & 1 year & - & - & $\begin{array}{l}\text { USA } \\
\text { (Seattle, WA) }\end{array}$ & Cycle & \multicolumn{4}{|c|}{ Sinusoidal relative humidity variation $[40 ; 60] \%$} \\
\hline Vereecken 11 & Exp. & 3 days & 14 & 35 & Belgium & Cycle & {$[0 ; 57]$} & 0.48 & \multicolumn{2}{|c|}{ No air renewal } \\
\hline Janssens 05 & Num. & 2 days & 48 & 130 & $\begin{array}{l}\text { Denmark } \\
\text { (summer) }\end{array}$ & Step & {$[0 ; 500]$} & 1.28 & Constant & 0.5 \\
\hline Steeman 09 & Num. & 1 year & 15 & 42 & Belgium & Cycle & {$[0 ; 70]$} & 0.62 & Constant & 0.4 \\
\hline
\end{tabular}


Appendix 3: Comparison of the various simulated cases based on the values computed at the yearly scale

\begin{tabular}{|c|c|c|c|c|c|c|}
\hline \multirow[b]{2}{*}{ Case } & \multirow{2}{*}{$\begin{array}{c}\text { Comfort [40: 50\%RH] } \\
\text { (Discomfort }(>60 \% \mathrm{RH}))\end{array}$} & \multicolumn{2}{|c|}{$\bar{w} \pm \sigma\left(\mathrm{kg}_{\mathrm{Vap}}\right)$} & \multicolumn{3}{|c|}{ Exceedance of safe level for mould growth (h) } \\
\hline & & Indoor siding & Outdoor siding & $\begin{array}{l}\text { Indoor siding } \\
\text { North (South) }\end{array}$ & $\begin{array}{l}\text { Insulating material } \\
\text { North (South) }\end{array}$ & $\begin{array}{l}\text { Outdoor siding } \\
\text { North (South) }\end{array}$ \\
\hline VT, VCR, VMP & $23.6 \%(31.6 \%)$ & $1.02 \pm 0.38$ & $26.8 \pm 5.7$ & $169(158)$ & $41(474)$ & $750(647)$ \\
\hline VT, RHS, VMP & $42.0 \%(20.0 \%)$ & $0.96 \pm 0.30$ & $26.9 \pm 5.7$ & $52(47)$ & $42(481)$ & $756(656)$ \\
\hline VT, RHS, CMP & $61.2 \%(18.4 \%)$ & $0.96 \pm 0.25$ & $26.9 \pm 5.7$ & $30(29)$ & $38(480)$ & $757(657)$ \\
\hline VP, VCR, VMP & $27.1 \%(27.3 \%)$ & $0.94 \pm 0.26$ & $28.8 \pm 7.0$ & $36(32)$ & $468(0)$ & $535(288)$ \\
\hline VP, VCR, CMP & $36.6 \%(25.5 \%)$ & $0.94 \pm 0.24$ & $28.8 \pm 7.1$ & $0(0)$ & $499(0)$ & $560(288)$ \\
\hline VP, RHS, VMP & $42.2 \%(19.2 \%)$ & $0.92 \pm 0.23$ & $28.6 \pm 6.9$ & $5(5)$ & $390(0)$ & 446 (298) \\
\hline VP, RHS, CMP & $62.3 \%(18.1 \%)$ & $0.93 \pm 0.20$ & $28.8 \pm 7.1$ & $0(0)$ & $652(0)$ & 684 (297) \\
\hline
\end{tabular}


Appendix 4: Comparison of the different simulated cases based on the values computed at the monthly scale

\begin{tabular}{|c|c|c|c|c|c|c|c|c|c|}
\hline \multirow{2}{*}{ Case } & \multicolumn{3}{|c|}{$\overline{\overline{Q_{V}}} \pm \sigma\left(\right.$ vol.h $\left.^{-1}\right)$} & \multicolumn{3}{|c|}{$\overline{\overline{P_{\text {Heating }}}} \pm \sigma(\mathrm{W})$} & \multicolumn{3}{|c|}{$\overline{\overline{\dot{g}_{\text {Walls }}}} \pm \sigma\left(\mathrm{g} \cdot \mathrm{h}^{-1}\right)$} \\
\hline & Year & October & January & Year $^{(1)}$ & October & January & Year $^{(1)}$ & October & January \\
\hline VT, VCR, VMP & & N.A. & & $218 \pm 143$ & $141 \pm 103$ & $352 \pm 97$ & $29.2 \pm 84.7$ & $30.8 \pm 92.2$ & $25.7 \pm 80.3$ \\
\hline VT, VCR, CMP & & N.A. & & $218 \pm 140$ & $141 \pm 99$ & $352 \pm 89$ & $5.7 \pm 8.2$ & $7.0 \pm 8.9$ & $3.8 \pm 5.6$ \\
\hline VT, RHS, VMP & $0.58 \pm 0.24$ & $0.75 \pm 0.13$ & $0.38 \pm 0.22$ & $218 \pm 130$ & $178 \pm 116$ & $303 \pm 92$ & $24.1 \pm 75.9$ & $26.6 \pm 84.0$ & $20.6 \pm 69.8$ \\
\hline VT, RHS, CMP & $0.62 \pm 0.17$ & $0.76 \pm 0.09$ & $0.47 \pm 0.13$ & $230 \pm 123$ & $181 \pm 113$ & $331 \pm 53$ & $4.9 \pm 8.8$ & $7.9 \pm 10.8$ & $1.7 \pm 3.1$ \\
\hline VP, VCR, VMP & & N.A. & & $244 \pm 156$ & $155 \pm 98$ & $400 \pm 100$ & $33.2 \pm 86.8$ & $36.0 \pm 94.7$ & $29.8 \pm 83.8$ \\
\hline VP, VCR, CMP & & N.A. & & $244 \pm 153$ & $153 \pm 94$ & $403 \pm 93$ & $14.3 \pm 14.3$ & $19.2 \pm 17.3$ & $14.6 \pm 11.1$ \\
\hline VP, RHS, VMP & $0.57 \pm 0.24$ & $0.76 \pm 0.10$ & $0.34 \pm 0.20$ & $240 \pm 128$ & $193 \pm 106$ & $335 \pm 74$ & $28.0 \pm 77.6$ & $31.6 \pm 86.0$ & $26.2 \pm 73.9$ \\
\hline VP, RHS, CMP & $0.61 \pm 0.19$ & $0.77 \pm 0.07$ & $0.41 \pm 0.12$ & $250 \pm 126$ & $195 \pm 105$ & $360 \pm 44$ & $13.7 \pm 14.4$ & $17.3 \pm 20.3$ & $17.9 \pm 7.2$ \\
\hline
\end{tabular}

VT: Vapour-Tight, VP: Vapour-Permeable, VCR: Ventilation at a Constant Rate, VMP: Variable Moisture Production, CMP: Constant Moisture Production

(1) Year referred to the heating season, which starts on $1^{\text {st }}$ September and ends on $31^{\text {st }}$ May 
